\title{
VARIATIONS OF STRONG EARTHQUAKE GROUND SHAKING IN THE LOS ANGELES AREA
}

\author{
By M. D. TRIFUNAC AND F. E. UdWAdia
}

\begin{abstract}
Accelerograms recorded at six stations in the metropolitan Los Angeles area during the Borrego Mountain, 1968, the Lytle Creek, 1970, and the San Fernando, 1971, earthquakes in southern California have been studied. In comparing the ground motions recorded during different earthquakes at each of the six stations and in correlations of these motions recorded at different stations during the same earthquake, those aspects of the analysis which emerge from this study and are relevant for seismic zoning have been emphasized.

It has been found that the patterns of strong ground shaking in this area depend predominantly on the mechanism and the distance of an earthquake source from a recording station and that the local soil conditions played only a minor role in modifying the ground motion at this particular area. It has been shown that the gross spectral characteristics of ground motion recorded at various stations can be approximately related by the seismic moment at the low-frequency end and by the stress drop at the high-frequency end.
\end{abstract}

\section{INTRODUCTION}

Numerous reports on the distribution of earthquake damage indicate that it can vary widely from one point to another and that the areas of intense damage may be highly localized (e.g., Jennings, 1971; Sozen et al., 1968; Hudson, 1972; Gutenberg, 1957; Richter, 1958). In addition to real differences of ground shaking a few significant factors contributing to such a distribution of damage are the overall quality of construction in the damaged area and the poor soil conditions leading to foundation failures, surface faulting, water inundation, and landsliding (e.g., Lee and Monge, 1966; Waseda University Publication, 1966; Alaska Earthquake, 1964).

The fact that the distribution of damage seems to follow some specific pattern has led many investigators to advance theories in an attempt to explain the observed patterns of damage in terms of the local amplification of ground motion, which are assumed to be related to the subsoil conditions. The simple and most frequently used theory based on vertically ascending $S$ waves through a set of parallel horizontal layers has been developed by Kanai and his co-workers in Japan (e.g., Kanai, 1957; Kanai and Tanaka, 1961; Kanai et al., 1953). This approach has been further developed and extended in the United States (e.g., Duke, 1958; Idriss and Seed, 1967; Schnabel et al., 1972) during the last 15 years. Although in some special cases such a simple theory can explain the gross effects of local subsoil conditions, especially at sites having exceptionally high impedance ratios (for example, in the metropolitan areas of Tokyo and Mexico City), no one has so far demonstrated that it can portray the gross features of the observed ground motions in areas characterized by less pronounced material contrasts. Nevertheless, during the last decade or so this method has gained considerable popularity, presumably for the following two reasons: (1) because of the relative ease with which local subsoil conditions 
can be obtained through seismic prospecting, bore holes, and trenching and (2) because the modeling of ground motion in parallel isotropic and homogeneous layers requires only a moderate theoretical and computational effort (e.g., Kanai et al., 1953; Herrera and Rosenblueth, 1965; Tsai, 1969 ; Sakurai and Takahashi, 1971).

It is well known that the spectral characteristics of strong earthquake ground motion are strongly dependent on the earthquake source mechanism (e.g., Brune, 1970; Aki, 1957; Aki, 1968; Trifunac, 1972a; Trifunac, 1972b), the earthquake radiation pattern (e.g., Suzuki, 1932; Udwadia, 1972; Haskell, 1969), the nature and the configuration of different geological discontinuities along the wave propagation path (e.g., Haskell, 1962; Aki and Larner, 1970; Gupta, 1966; Sato, 1963; Hudson, 1962; Abubakar, 1962; Tsai, 1969; Trifunac, 1971a), and the surface topography (e.g., Boore, 1972; Trifunac, 1973a) in addition to possible local subsoil effects. Nevertheless, there is a significant effort, currently under way at many institutions engaged in earthquake engineering research, aimed at introducing the local soil effects as an important factor into the characterization of the amplitudes and the frequency content of strong ground shaking. Since it is clearly of great importance to predict whether particular regions may experience high levels of heavy shaking and whether those can be correlated with the local subsoil conditions, it is timely to reexamine this question in the light of the most recently acquired strong-motion data for the Los Angeles metropolitan area. A similar study was carried out for the El Centro strong-motion accelerograph site in Imperial Valley, California (Udwadia and Trifunac, 1973) by comparing the spectra of 15 strong-motion earthquakes, all recorded at the same station. For the El Centro site we found that the local subsoil conditions play an insignificant role in determining the overall spectral trends of the strong earthquake ground motion and that the amplitudes and the shape of the spectra strongly depend on the source mechanism and the distance from the earthquake source.

In most studies of damage distribution patterns, when the explanation is sought in terms of assumed predominant effects of local subsoil conditions, a correlation of the spatial distribution of some index of damage with a salient feature (typically the depth of alluvium) of the proposed subsoil model is made. There is, however, no basis for the assumption that the pattern of damage will be the same when the next earthquake occurs. Thus, it is necessary to examine several recordings of strong ground motion at the same point, caused by different earthquakes, before the possible dominant effects of the local subsoil conditions can be established.

The purpose of this paper is to present such a comparison of strong earthquake ground motion recorded at six selected accelerograph stations in the metropolitan Los Angeles area during three moderate earthquakes in Southern California. The analysis in this paper focuses on the question of whether the local subsoil conditions can be detected from repeated measurements of strong shaking. Having shown that there are no prevalent "site periods" at the stations selected, we proceed to examine the coherence of ground displacements in the Los Angeles and Hollywood areas by comparing the radial, transverse, and vertical components of ground motion at four stations during the same earthquake. This analysis shows that seismic waves whose frequencies are less than one to several Hertz propagate from Hollywood to Los Angeles and vice versa with only a minor distortion.

Although the three earthquake recordings studied at the six stations are certainly not adequate to reach any definite conclusions, our results indicate, so far, a lack of strong local site periods, in agreement with several previous investigators (Hudson, 1972; Byerly, 1947; Wiggins, 1964; Udwadia and Trifunac, 1973). Such findings raise the question of the usefulness of seismic zoning and the preparation of seismic risk maps for 
the Los Angeles area based on local amplifications related to subsoil conditions alone and reflected in predominant site periods.

\section{Station and Earthquake Characteristics and the Strong-Motion DATA USED}

The present work is restricted by the availability of usable records from all three earthquakes at the selected stations. Since Los Angeles is one of the best instrumented metropolitan areas of the world (currently instrumented with about 600 accelerographs), it is worthwhile to point out that it will be necessary to wait for many years before a

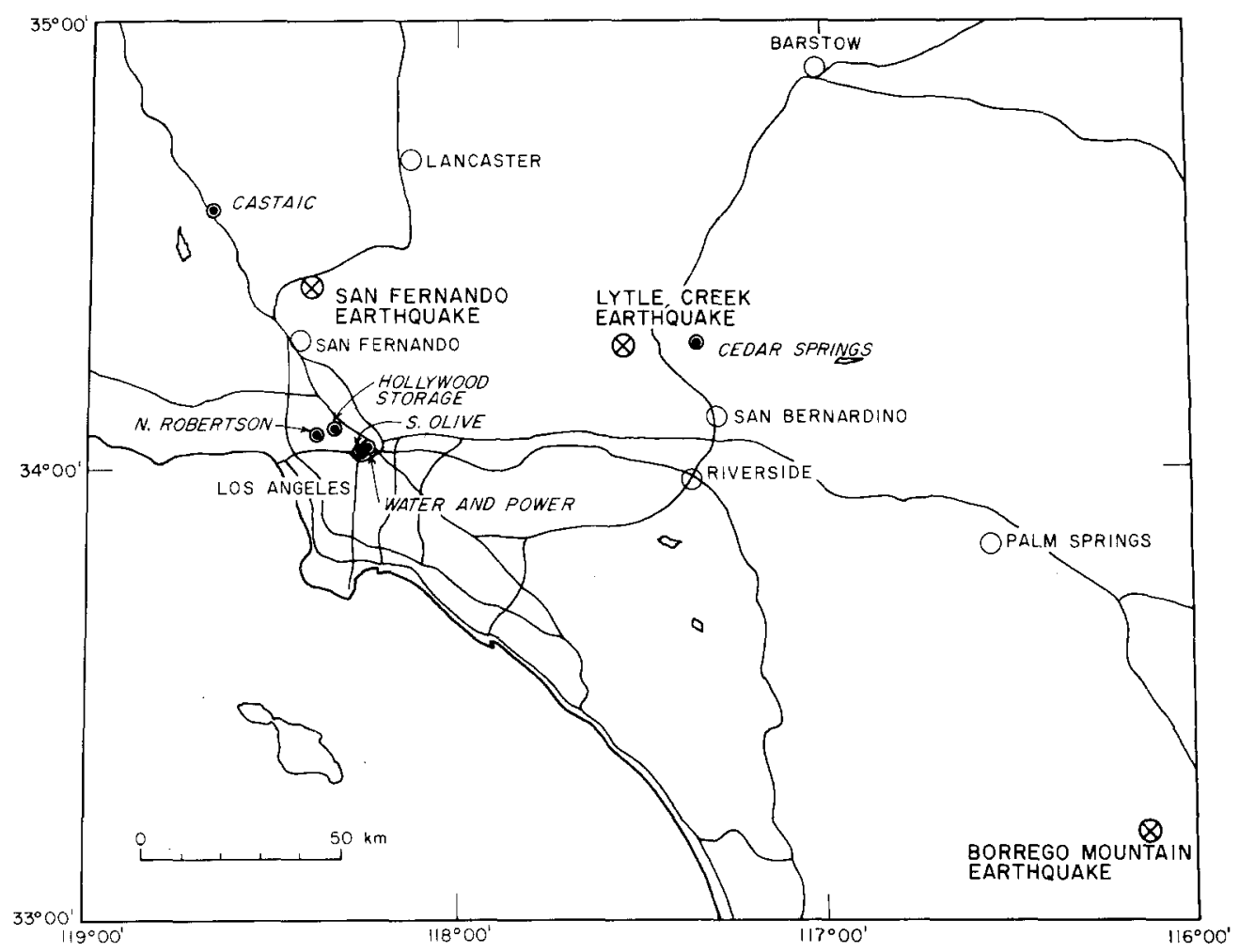

FiG. 1. Map indicating locations of the six stations and the epicenters of the three earthquakes used in this study.

similar study can become possible in other cities where the strong-motion recording program is still only in its early stage of development. Since the soundness of any microzonation program can be best justified by actual measurements of strong ground motion in the particular area of interest, it is clear that the general results and conclusions dealing with this important problem are not to be expected in the near future.

The six accelerograph stations used in this analysis are shown in Figure 1. Four of the stations (N. Robertson, Hollywood Storage, S. Olive, and Water and Power) are centrally located in the Los Angeles and Hollywood areas while the remaining two (Castaic and Cedar Springs) are on the outskirts of the metropolitan area. A summary of station characteristics, including the geological setting, depth of alluvium and the epicentral distances from the three earthquakes studied in this paper, are given in Table 
1. As seen from this table, the four centrally located stations (Figure 1) are all on deep alluvium ranging from about $6,000 \mathrm{ft}$ to over $12,000 \mathrm{ft}$.

The epicenters of the Borrego Mountain, the Lytle Creek, and the San Fernando, California, earthquakes are also indicated in Figure 1. Other pertinent characteristics of these shocks are summarized in Table 2. These events are small to moderate sized earthquakes that occur frequently in Southern California. In fact, on the average a shock similar to the Lytle Creek earthquake occurs once a year in California, while the shocks comparable to the Borrego Mountain or the San Fernando earthquakes occur once in the time span of 5 years. The source mechanism of the latter two earthquakes has been investigated in detail and a summary of pertinent source characteristics is shown in Table 2.

The digital data for 18 strong-motion accelerograms (recorded at six stations during these three different earthquakes) have been obtained from the Volume II series of magnetic tapes processed at the Earthquake Engineering Research Laboratory of the California Institute of Technology. These tapes contain equally spaced accelerograms (corrected for instrument response and band-pass filtered between 0.07 and $25 \mathrm{~Hz}$ ) and integrated velocity and displacement data. Detailed identification of these accelerograms is given in Table 3, which lists the $\log$ numbers and the reference numbers for all 18 records.

\section{Investigation of Possible Site Periodicities}

If the local soil conditions modify the incoming seismic waves in a simple and significant way, then we would expect that the same frequencies would always be amplified or deamplified irrespective of the earthquake source mechanism or the direction from which seismic waves arrive. There is little doubt that the geological discontinuities may have a great influence on the recorded motions, but we expect that these effects are strongly dependent on the three-dimensional nature of soil deposits and on the direction of the arriving waves (e.g., Trifunac, 1971a). In other words, we expect that the pattern of amplification caused by the local site conditions and the transmission path has little chance of being repeated during any sequence of recorded earthquakes, unless these would occur on the same fault and would have identical source mechanisms.

The Fourier amplitude spectra in Figures 2 through 7 have been computed by the Fast Fourier Transform algorithm using the complete digitized record (Hudson et al., 1972b). Fourier amplitudes were then smoothed over an interval of $\frac{1}{2} \mathrm{~Hz}$ by using a symmetric moving filter whose weights decreased linearly from the filter midpoint to the filter end points $\frac{1}{4} \mathrm{~Hz}$ away. We expect that this filter eliminates most of the processing variations in the computed spectra and brings out the important spectral amplitudes of the recorded motion (Udwadia, 1972). The smoothed Fourier amplitude spectra in Figures 2 through 7 are identified by BM68 for the Borrego Mountain, 1968, earthquake, by LC70 for the Lytle Creek, 1970, earthquake, and by SF71 for the San Fernando, 1971, earthquake. The spectra are presented from 0 to $15 \mathrm{~Hz}$ only, since with the linear scales used the Fourier amplitudes become negligible for higher frequencies.

To study possible site periodicities at nearby stations, it is convenient to rotate all recorded accelerograms so that the two horizontal components point to north and east. The actual directions of these components are, of course, not important for the present paper since the simplified theory assumes that the possible local amplifications are independent of the direction of the wave arrivals.

Detailed analysis of all spectra in Figures 2A, B, C through 7A, B, C shows that there are no detectable predominant site periods at any of the six stations. A few of the cases in which several peaks of one spectrum approximately match the corresponding one or 


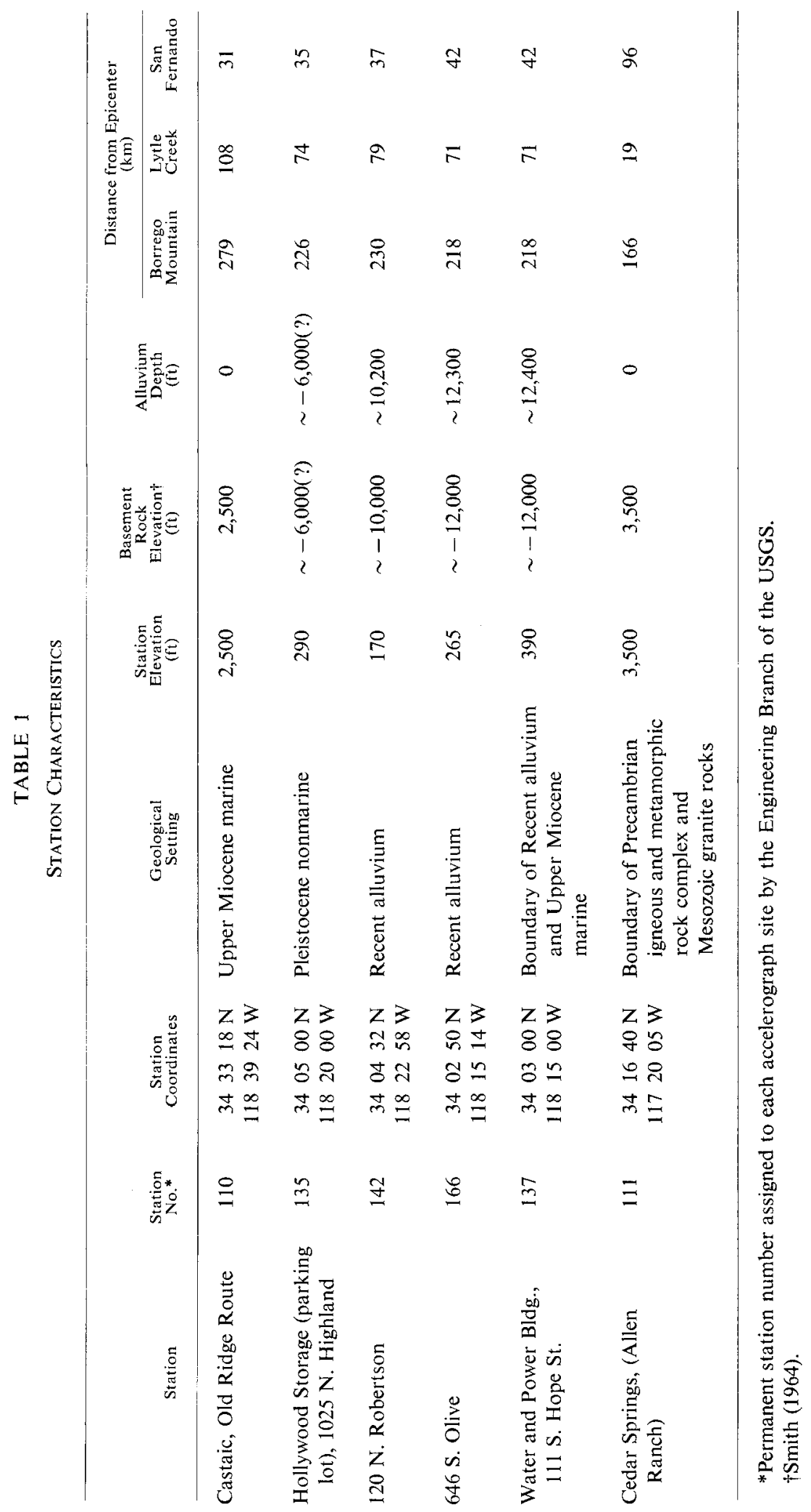


TABLE 2

EARTHQUake ChaRacteristics

\begin{tabular}{|c|c|c|c|}
\hline Parameters & $\begin{array}{l}\text { Borrego Mountain } \\
\text { Earthquakea, } \\
\text { April 8, 1968, } \\
\text { 18:30 PST }\end{array}$ & $\begin{array}{l}\text { Lytle Creek Earthquakeb, } \\
\text { September 12, 1970, } \\
6: 30 \text { PST }\end{array}$ & $\begin{array}{l}\text { San Fernando Earthquake, } \\
\text { February 9, 1971, } \\
6: 00 \text { PST }\end{array}$ \\
\hline Local magnitude, $M_{L}$ & 6.4 & 5.4 & $6.4^{c}$ \\
\hline $\begin{array}{l}\text { Seismic moment, } M_{o}^{d} \\
\quad(\text { dyne-cm) }\end{array}$ & $\begin{array}{l}\bar{M}_{o}(P)=10 \times 10^{25} \\
\bar{M}_{o}(S)=6.6 \times 10^{25} \\
\bar{M}_{o}(F)=3.6 \times 10^{25}\end{array}$ & $M_{o}=1 \times 10^{24}$ & $\begin{array}{l}\bar{M}_{o}(P)=0.47 \times 10^{26 c} \\
\bar{M}_{o}(S)=0.88 \times 10^{26 c} \\
\bar{M}_{o}(S S)=0.75 \times 10^{25 c} \\
\bar{M}_{o}(F)=1.3 \times 10^{26 c}\end{array}$ \\
\hline $\begin{array}{l}\text { Source dimension, } \\
\quad r=\text { equivalent radius }(\mathrm{km}) \\
L=\text { fault length }(\mathrm{km})\end{array}$ & $\begin{aligned} \bar{r}(P) & =14 \\
\vec{r}(S) & =23 \\
L / 2(F) & =17\end{aligned}$ & $\begin{array}{c}3 \text { spectral } \\
5 \text { aftershocks }\end{array}$ & $\begin{array}{l}7 \text { near-field studiese } \\
\bar{r}(P)=15^{c} \\
\bar{r}(S)=12^{c}\end{array}$ \\
\hline Stress drop ( $\zeta$-bars) & 5 & 7 & $30-70^{e}$ \\
\hline Strike & $\sim \mathrm{N} 48^{\circ} \mathrm{W}^{a}$ & $\mathrm{~N} 26^{\circ} \mathrm{W}$ or $\mathrm{N} 64^{\circ} \mathrm{E}^{f}$ & $\mathrm{~N} 64^{\circ} \mathrm{W}-\mathrm{N} 72^{\circ} \mathrm{W}^{e}$ \\
\hline Dip & $\sim$ vertical $^{a}$ & - & $45^{\circ}-52^{\circ} N E^{e}$ \\
\hline
\end{tabular}

${ }^{a}$ Hanks and Wyss (1972).

${ }^{b}$ T. C. Hanks (personal communication, 1973).

${ }^{c}$ Wyss and Hanks (1972).

d $P$, determined from $P$-wave spectra; $S$, determined from $S$-wave spectra; $F$, determined from field observations; $S S$, determined from surface-wave data.

${ }^{e}$ Trifunac (1974).

${ }^{s}$ Brian Tucker (personal communication).

TABLE 3

Data References

\begin{tabular}{|c|c|c|c|c|c|c|c|}
\hline \multirow[b]{2}{*}{ Station } & \multirow[b]{2}{*}{$\begin{array}{l}\text { Station } \\
\text { No. }\end{array}$} & \multicolumn{2}{|c|}{$\begin{array}{c}\text { Borrego Mountain } \\
\text { Earthquake }\end{array}$} & \multicolumn{2}{|c|}{$\begin{array}{l}\text { Lytle Creek } \\
\text { Earthquake }\end{array}$} & \multicolumn{2}{|c|}{$\begin{array}{c}\text { San Fernando } \\
\text { Earthquake }\end{array}$} \\
\hline & & $\begin{array}{l}\text { Caltech } \\
\text { Log } \\
\text { No. }^{*}\end{array}$ & $\begin{array}{c}\text { Caltech } \\
\text { Reference } \\
\text { No. } \dagger\end{array}$ & $\begin{array}{l}\text { Caltech } \\
\text { Log } \\
\text { No.* }\end{array}$ & $\begin{array}{l}\text { Caltech } \\
\text { Reference } \\
\text { No. }{ }^{\dagger}\end{array}$ & $\begin{array}{c}\text { Caltech } \\
\text { Log } \\
\text { No. }\end{array}$ & $\begin{array}{l}\text { Caltech } \\
\text { Reference } \\
\text { No. }^{+}\end{array}$ \\
\hline $\begin{array}{l}\text { Castaic, } \\
\quad \text { Old Ridge Route }\end{array}$ & 110 & 68.069 & - & 70.005 & W346 & 71.007 & D056 \\
\hline $\begin{array}{l}\text { Hollywood Storage, } \\
\text { (Parking lot), } \\
1025 \text { N. Highland }\end{array}$ & 135 & 68.071 & Y380 & 70.012 & W347 & 71.155 & D058 \\
\hline $\begin{array}{l}120 \text { N. Robertson, } \\
\text { 2nd basement }\end{array}$ & 142 & 68.051 & - & 70.018 & W352 & 71.111 & F095 \\
\hline $\begin{array}{l}646 \text { S. Olive, } \\
\text { basement }\end{array}$ & 166 & 68.039 & - & 70.035 & X367 & 71.114 & F098 \\
\hline $\begin{array}{l}\text { Water and Power } \\
\text { Bldg., } 111 \text { S. Hope } \\
\text { St., "B" level }\end{array}$ & 137 & 68.043 & - & 70.024 & X358 & 71.059 & E078 \\
\hline $\begin{array}{l}\text { Cedar Springs } \\
\text { (Allen Ranch) }\end{array}$ & 111 & 68.061 & - & 70.011 & W335 & 71.145 & $\mathrm{O} 202$ \\
\hline
\end{tabular}

* Caltech $\log$ No. is a string of two numbers separated by a period. The first number gives the year in which the earthquake occurred. The second is the serial number of the record as it was received at the Earthquake Engineering Research Laboratory.

$\dagger$ Caltech Reference No. consists of one letter and a three-digit number. The letter, e.g., "D" indicates that the corrected accelerograms and computed velocity and displacement curves have been obtained from Part $D$ of the Volume II Reports and magnetic tapes. The three-digit number is the Caltech reference number assigned to each accelerogram in Volume I. (For further details on the data libraries and organization, see Hudson et al., 1969, 1971, 1972a, b). 

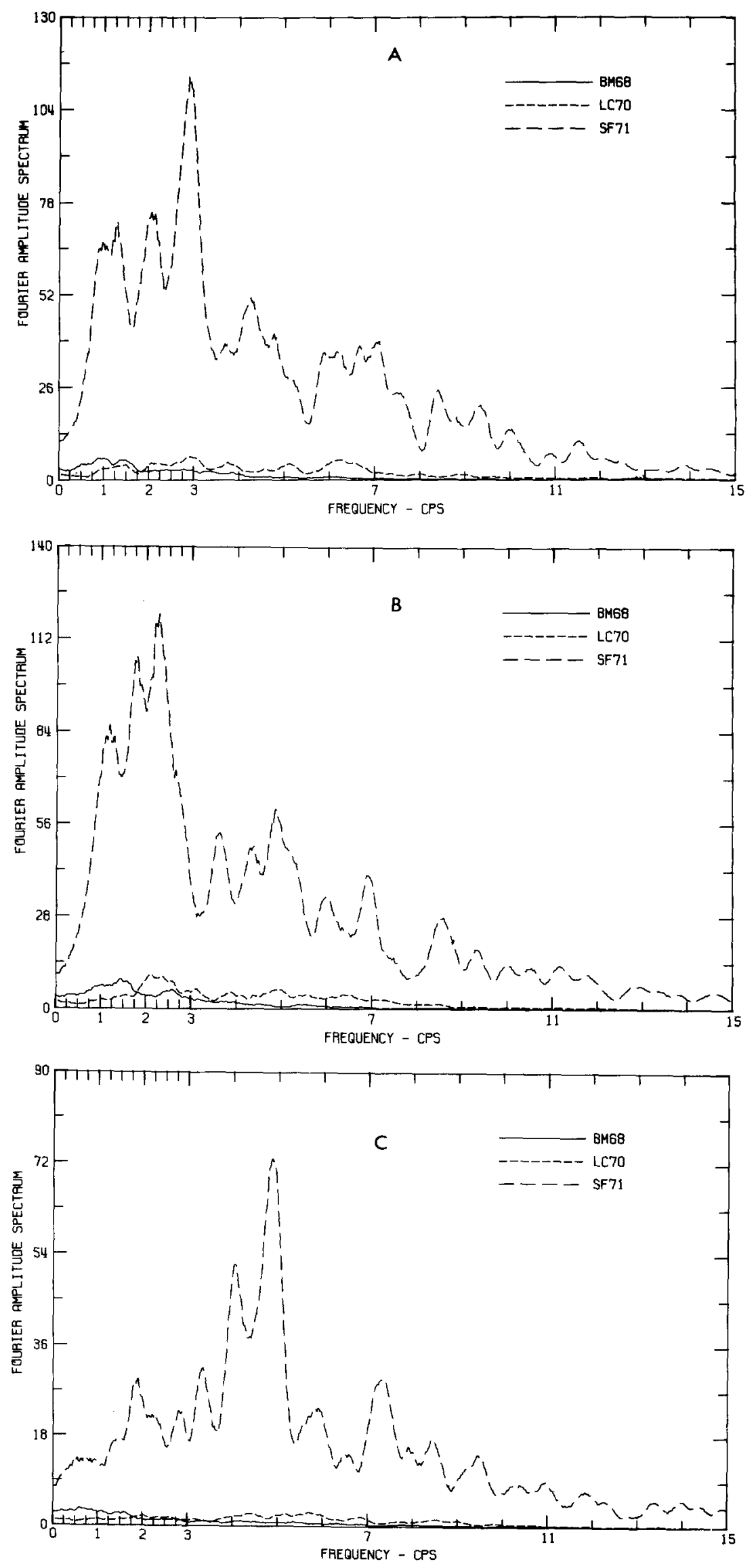

Fig. 2. Smoothed Fourier amplitude spectra-Castaic. (A) north comp., (B) east comp., (C) down comp. 

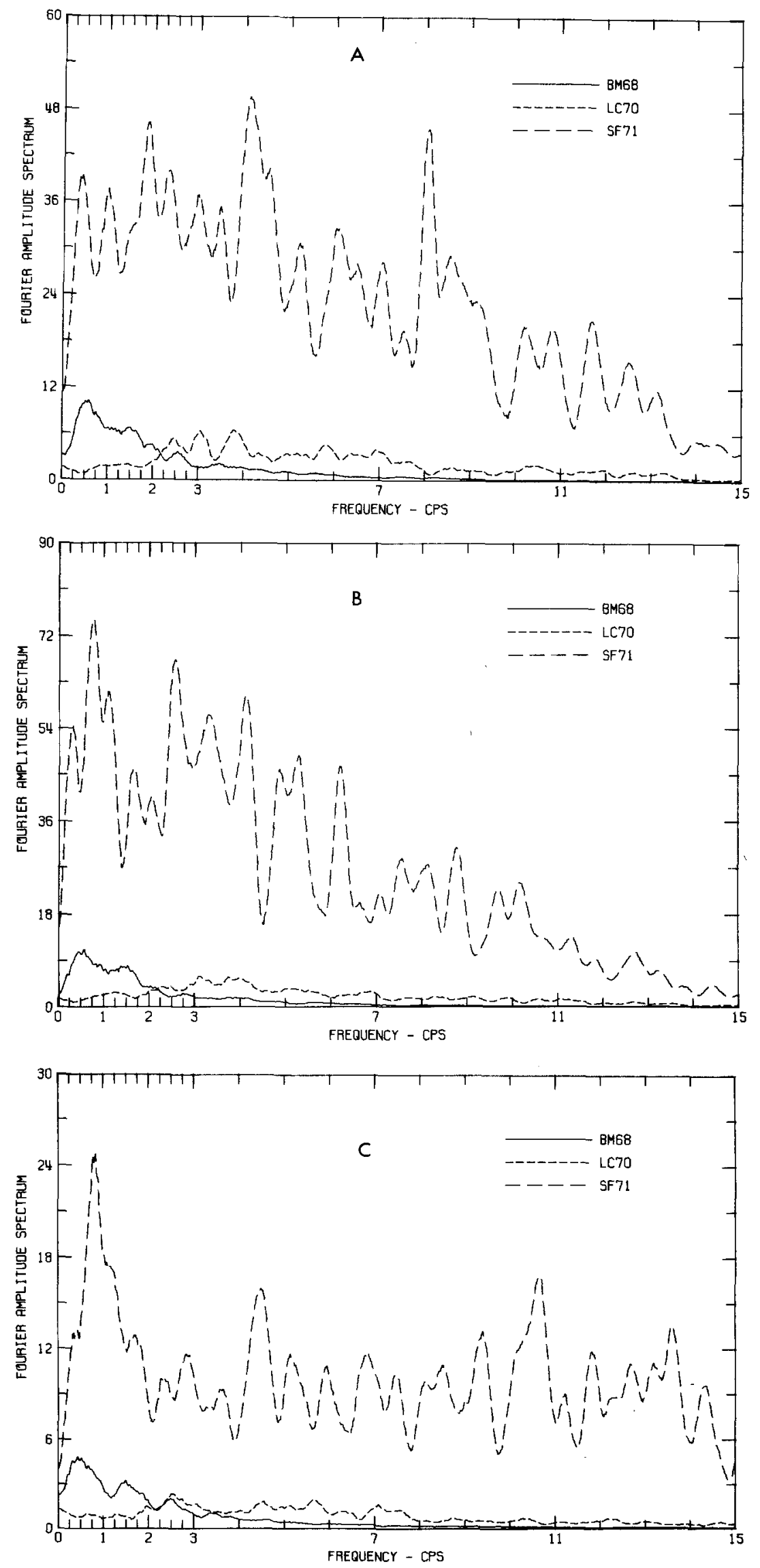

FIG. 3. Smoothed Fourier amplitude spectra-Hollywood Storage. (A) north comp., (B) east comp., (C) down comp. 

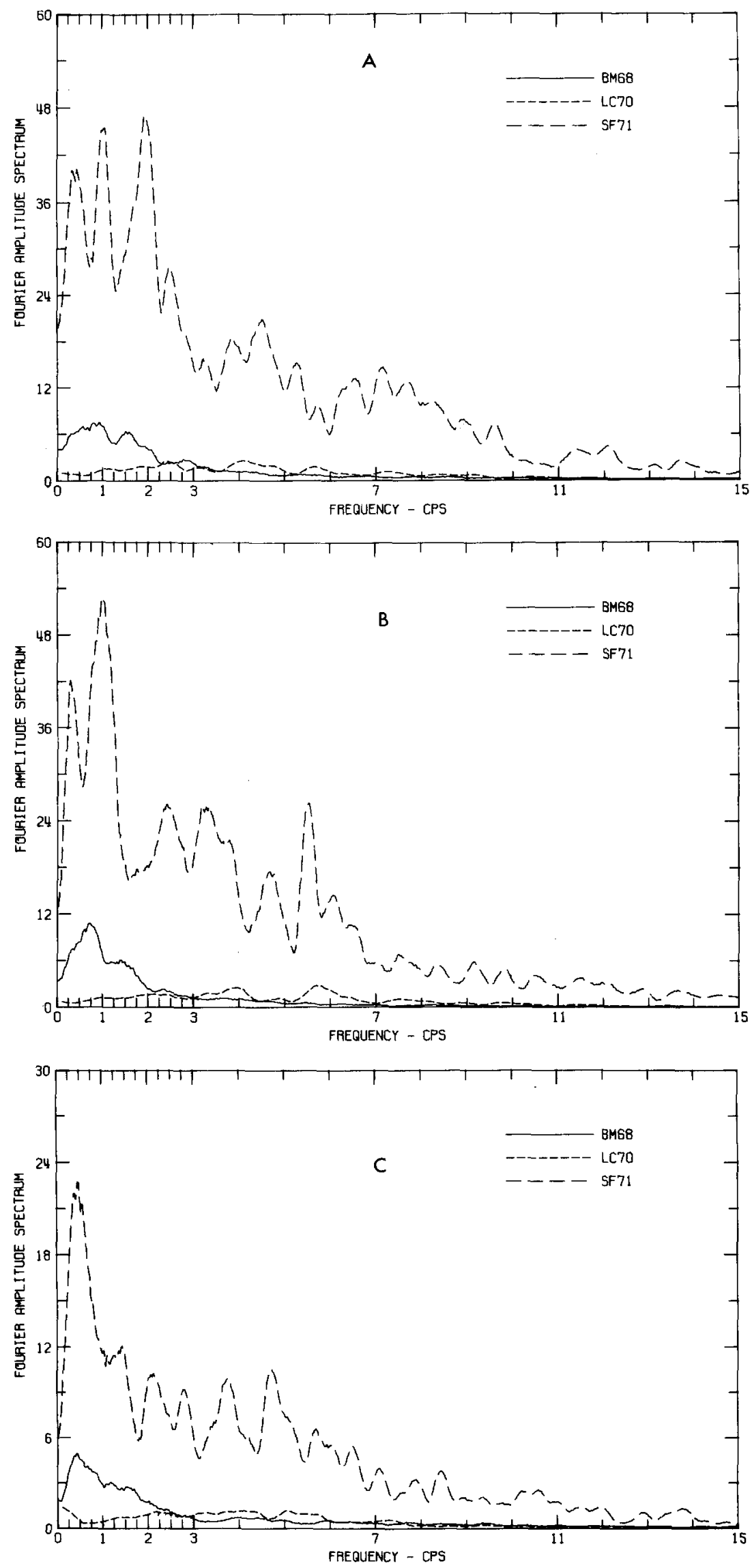

Fig. 4. Smoothed Fourier amplitude spectra-N. Robertson. (A) north comp., (B) east comp., (C) down comp. 

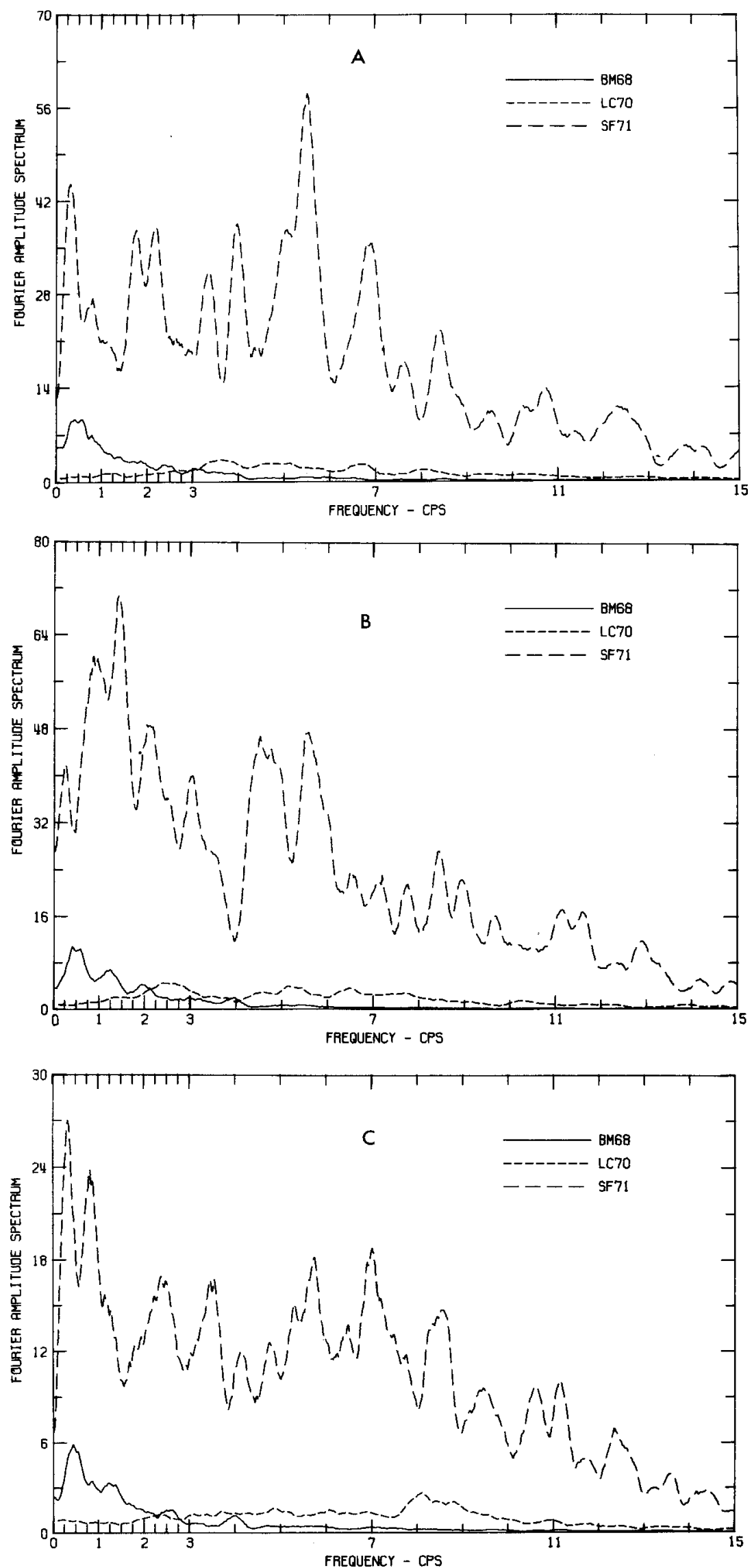

Fig. 5. Smoothed Fourier amplitude spectra-S. Olive. (A) north comp., (B) east comp., (C) down comp. 

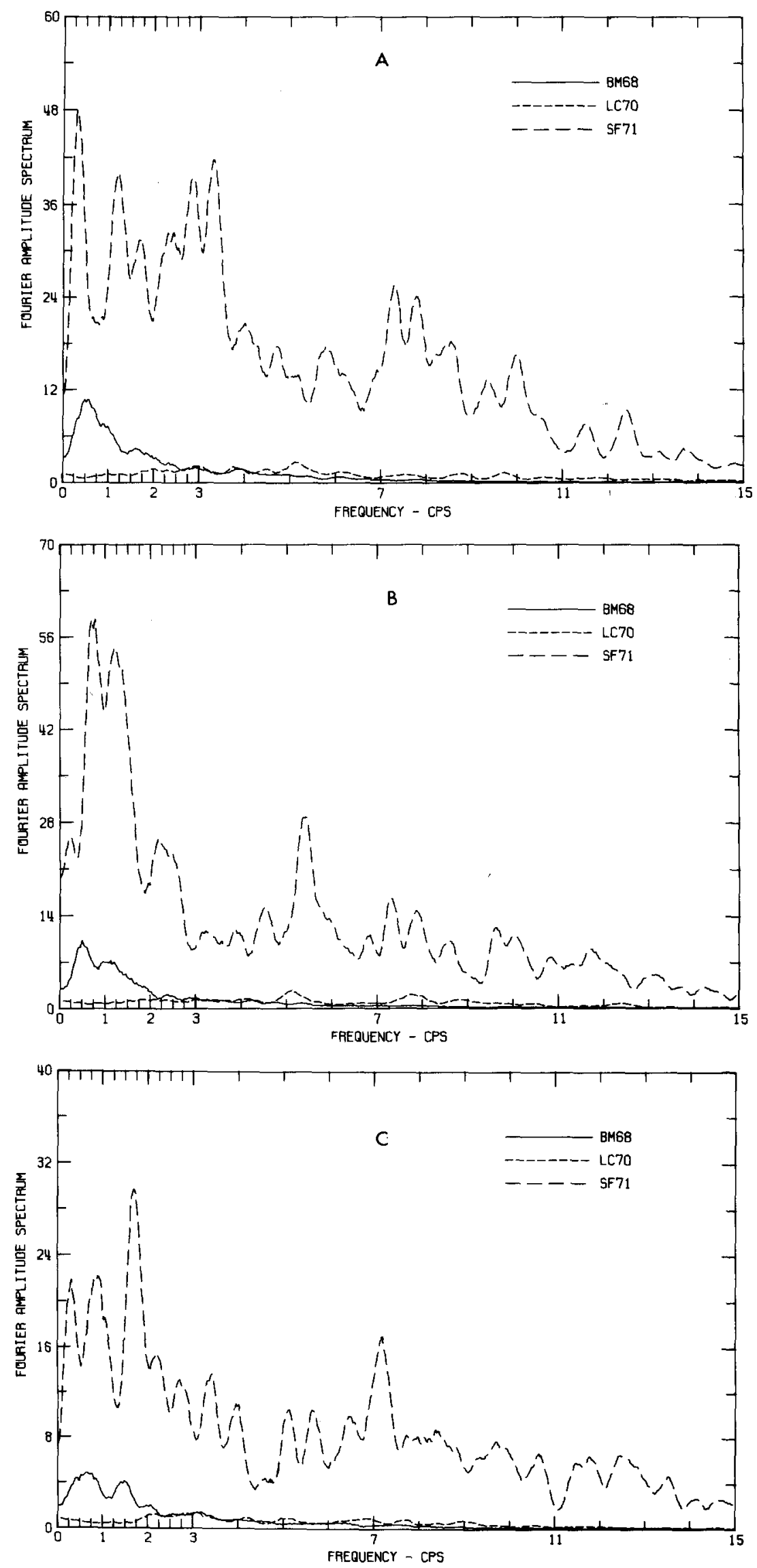

FIG. 6. Smoothed Fourier amplitude spectra-Water and Power. (A) north comp., (B) east comp., (C) down comp. 

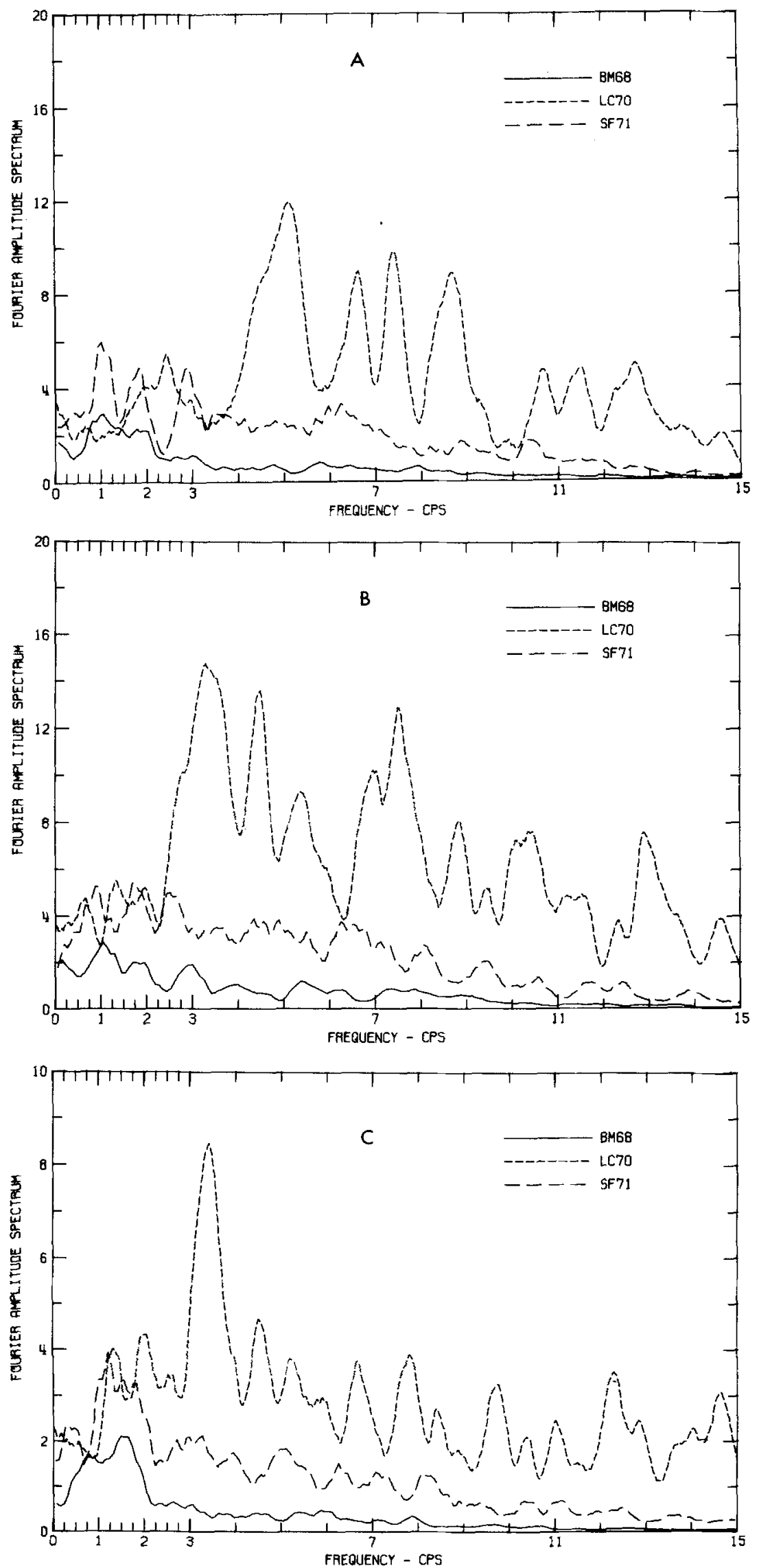

Fig. 7. Smoothed Fourier amplitude spectra-Cedar Springs. (A) north comp., (B) east comp., (C) down comp. 
two peaks in the other spectrum can be explained by random chance alone. Such peak matchings could, of course, be asserted more rigorously by taking all of the significant peaks from all of the spectra in Figure 2 through 7 and calculating how many peaks would be expected to match the peaks in the other spectra on the basis of random chance alone. This approach has been considered in some detail by Udwadia (1972) but does not appear to be necessary here, since the visual analysis of Figures $2 \mathrm{~A}, \mathrm{~B}, \mathrm{C}$ through 7A, B, C clearly demonstrates the point.

The most important consideration of all simple engineering studies of this type would be the repeatability of the interpreted site periodicities. Unless it can be shown that several earthquakes consistently lead to Fourier spectra of similar shape having similarly located peaks, there is little justification for modeling the observed spectra by the simple models which nonetheless must be characterized with numerous parameters: By an appropriate selection of these parameters, in most cases, it is possible to match certain characteristic spectral trends or even several peaks. However, since there is no unique way of selecting the appropriate model and its parameters, there is little or no chance that this model will stand the critical test of future earthquakes.

If one had only the north-south accelerograms of the Borrego Mountain, 1968, and the San Fernando, 1971, earthquakes (Figure 7A), for example, one might be tempted to interpret the similar spectral shapes between 0 and $2.5 \mathrm{~Hz}$ to be indicative of some prominent local site effects. That this agreement of the spectral shapes may merely be the result of a chance occurrence is indicated by the third spectral curve for the Lytle Creek, 1970, earthquake, which does not resemble the shape of the other two curves in any way. This example illustrates again the importance of the repeatability of measured spectra before the appropriate models and interpretations can be developed.

Many localized peaks and troughs superimposed on the overall spectral trends in Figures $2 \mathrm{~A}, \mathrm{~B}, \mathrm{C}$ through $7 \mathrm{~A}, \mathrm{~B}, \mathrm{C}$ no doubt are caused by the local site effects. Their relative position and amplitudes, however, depend on the three-dimensional nature of the local site configuration and the direction and nature of the arriving seismic waves, a feature that changes from one earthquake to another. The frequency band in which these effects take place is determined by the ratio of the incident wavelengths to the size of the local irregularities (e.g., Trifunac, 1971a, 1973a).

It should be noted here that numerous highs and lows of the computed spectra, particularly for the low-frequency end of the spectrum, may not be caused by the local site effects but may be the result of the transmission path and the source mechanism characteristics of each individual site-earthquake combination. While the overall average spectral trends are governed by the seismic moment and the stress drop of an earthquake (Trifunac, 1973b), departures of measured spectra from the average trend can be explained by the radiation patterns, the directivity function describing the effects of a propagating dislocation, and the transmission path effects leading to surface waves (e.g., Trifunac, 1971a, b). These features of the spectra in Figures 2A, B, C through $7 \mathrm{~A}, \mathrm{~B}, \mathrm{C}$ will become clear when we consider the radial and transverse components and the overall coherence of the recorded ground motions in the following section.

\section{Changes of Ground Motion with Distance}

The well-known result of numerous wave propagation studies involving scattering and diffraction is that for the waves whose wavelength is long compared to the size of the irregularity, the wave amplitudes are scarcely affected and essentially propagate as if there were no irregularity at all (e.g., Trifunac, 1971a; Trifunac, 1973a). For the waves to "feel" the geological strata and the topographic features, their wavelengths have to be 
comparable to or shorter than the characteristic dimensions of these features. Thus, it might be expected that the ground displacments, which accentuate the long-period components of ground motion, might be coherent up to distances comparable to the wavelengths involved. On the other hand, the properties of ground accelerations representing the characteristics of the high-frequency end of the spectrum are associated with the short wavelengths and are quite sensitive to material discontinuities and surface topography. To provide more quantitative support for these assertions, we study the data from four stations: Hollywood Storage (HOLS), S. Olive (SOLV), N. Robertson (NROB), and Water and Power (WOPO) (Figure 1).

Figures 8,9 , and 10 present the acceleration, velocity, and displacement curves at these four stations for the Borrego Mountain, the Lytle Creek, and the San Fernando earthquakes. To ease comparison of these motions recorded at the four different stations, recording directions have been rotated to radial, transverse, and vertical. The records were next shifted relative to each other along the time axis so as to line up approximately the prominent displacement wave forms at all four stations. This shifting in time does not result in a display of the relative real time for these four stations, since we have not accounted for the relative delays caused by the different epicentral distances. A detailed discussion of how such records might be lined up to study surface-wave dispersion has been presented by Hanks (1974) and will not be repeated here. The purpose of our present analysis is to compare the corresponding wave forms with the approximate relative time only. The data in Figures 8 and 10 have been high-pass filtered to above $\frac{1}{5} \mathrm{~Hz}$, while the data in Figure 9 have been high-pass filtered to above $\frac{1}{2} \mathrm{~Hz}$. This elimination of long-period waves (Hudson et al., 1971) has been carried out to enhance the reliability with which the correlations of motions at different stations can be made.

The transverse displacement components in Figure 8 of the Borrego Mountain earthquake contain the most prominent wave forms for this event. Since the strike of this vertical strike-slip fault has been close to $\mathrm{N} 50^{\circ} \mathrm{W}$, these waves most probably represent Love waves. The transverse displacement wave forms are nearly identical in shape at all four stations but vary in amplitudes. At the Hollywood Storage and N. Robertson sites these motions appear smaller, while the radial amplitudes are somewhat larger at these sites than at the S. Olive and Water and Power sites. Since the azimuths of all four stations are almost identical with respect to the epicenter of the Borrego Mountain earthquake (Figure 1), one explanation for these amplitude variations could be that the nominal orientations of these instruments are slightly off. Geometric spreading would account only for differences in amplitudes of several percentage points. The waves in question have periods ranging from 3 to $5 \mathrm{sec}$ which correspond to the wavelengths ranging from about 10 to $20 \mathrm{~km}$. Since the largest spacing of these stations is about $12 \mathrm{~km}$, these waves could be significantly affected by the changes in the alluvium depth as they propagate toward the northwest. A few kilometers north of the N. Robertson and Hollywood Storage sites is the Malibu-Cucamonga fault zone and 4 to $5 \mathrm{~km}$ to the northwest are the Santa Monica Mountains. For this reason, 4 to $5 \mathrm{~km}$ northwest of these two stations the depth of alluvium probably shallows very rapidly (Smith, 1964), and the rapidly rising basement rocks may reflect a significant proportion of incident surface-wave energy back in the southeastern direction. In spite of all these complications, which undoubtedly contribute unknown amounts to the observed motions, the longperiod wave forms shown in Figure 8 are quite coherent. The Water and Power and $\mathrm{S}$. Olive sites are separated by less than $1 \mathrm{~km}$ and for wavelengths of 10 to $20 \mathrm{~km}$ these two stations should show essentially the same ground displacements. The fact that the amplitudes and the nature of differences of recorded motions at these two sites are comparable to the differences between these two stations and those at N. Robertson and 

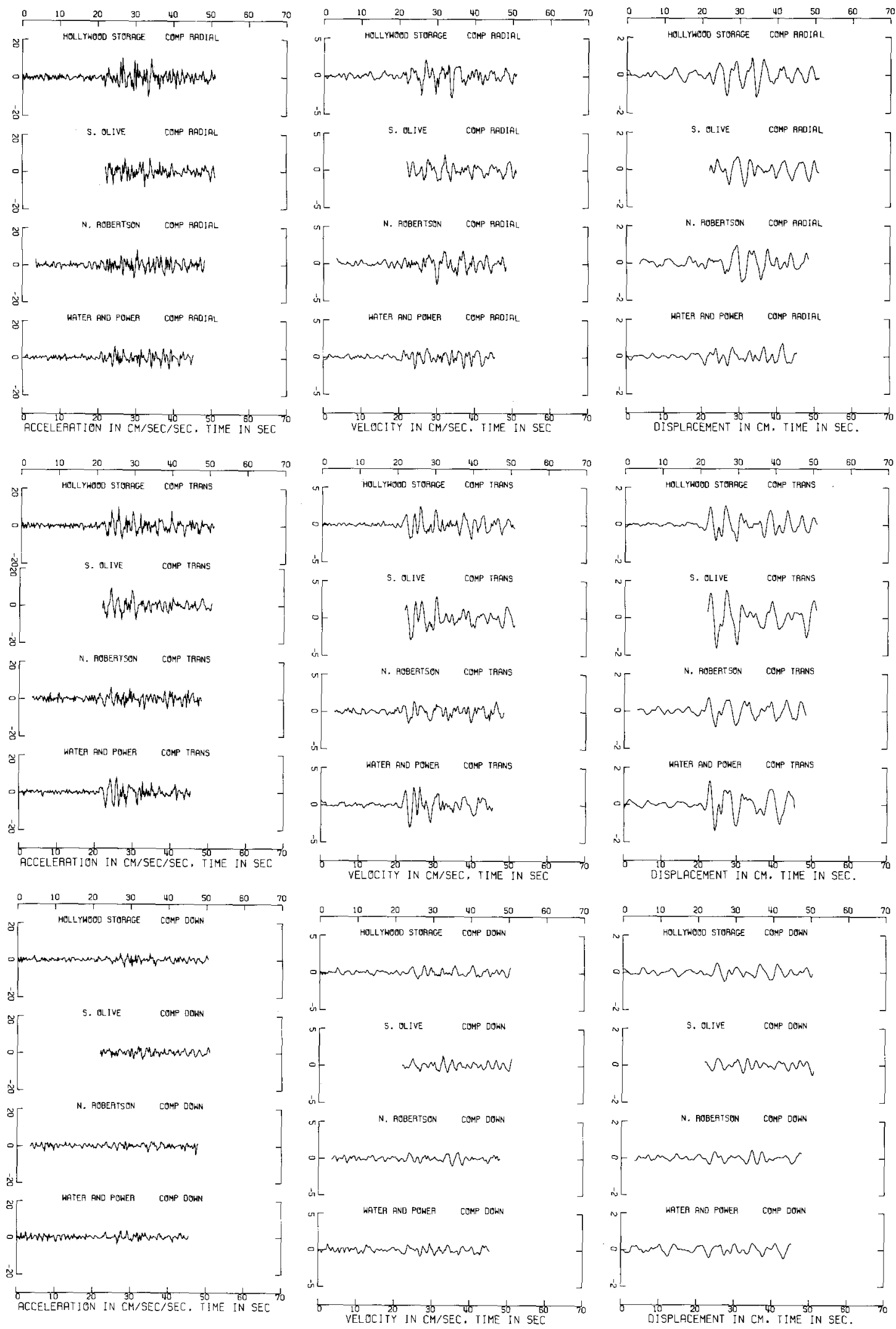

FIG. 8. Ground accelerations, velocities, and displacements recorded at the four stations in the Los Angeles and Hollywood area during the Borrego Mountain, California, earthquake of 1968. 


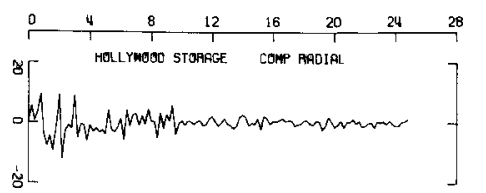

[W. OLIVE COMP RADIal
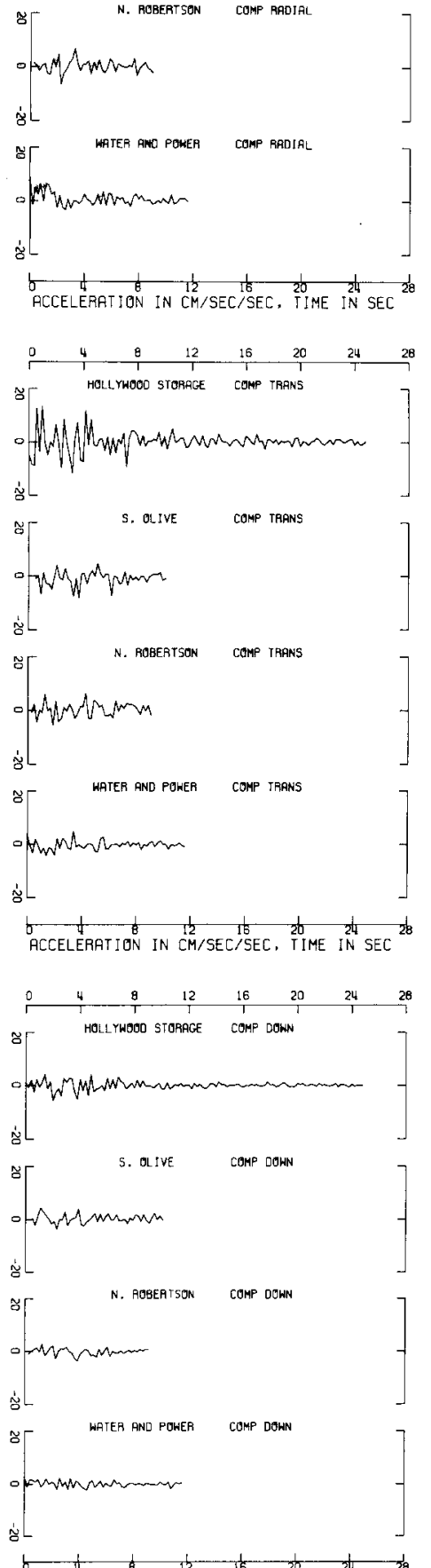

ACCELERATION IN CM/SEC/SEC. TIME IN SEC



- S. OLIVE
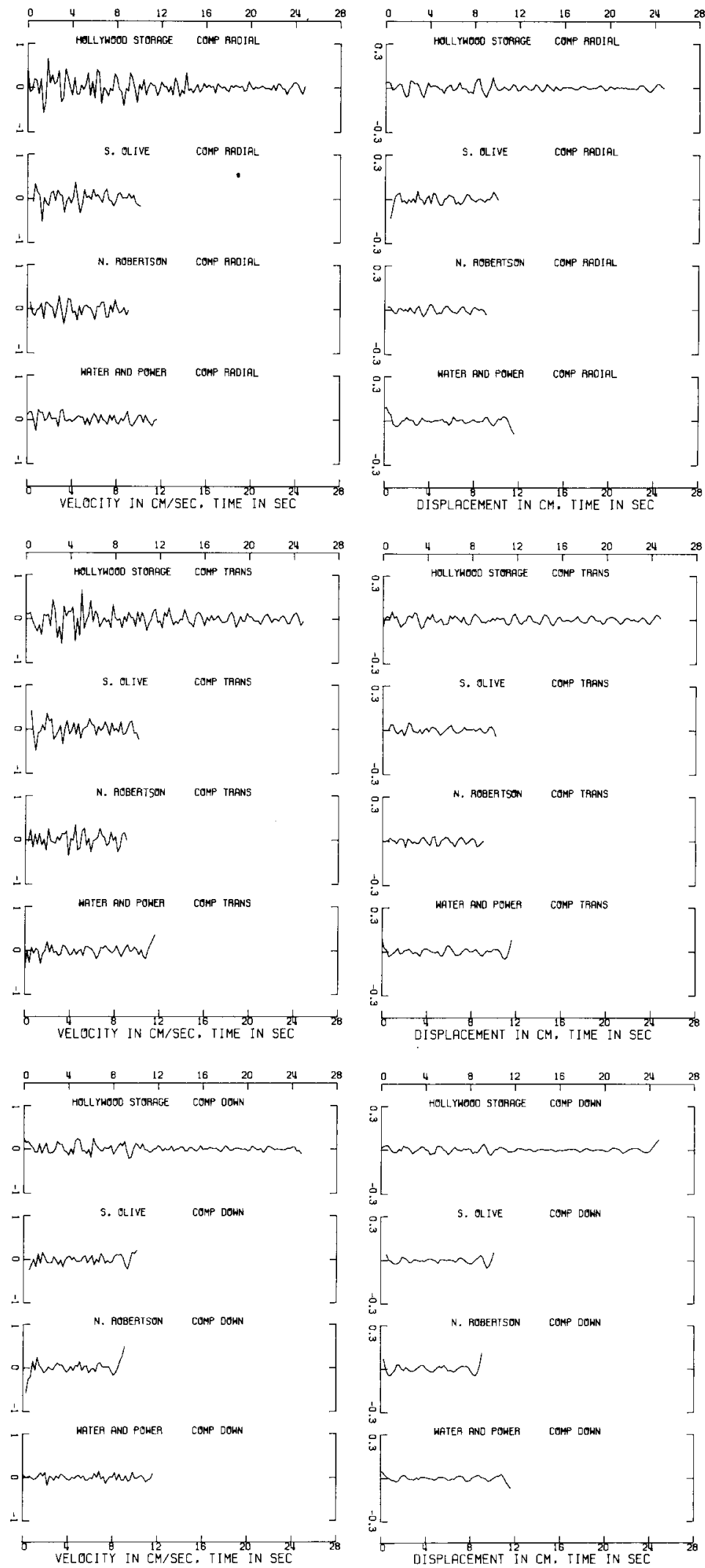

FIG. 9. Ground accelerations, velocities, and displacements recorded at the four stations in the Los Angeles and Hollywood area during the Lytle Creek, California, earthquake of 1970. 


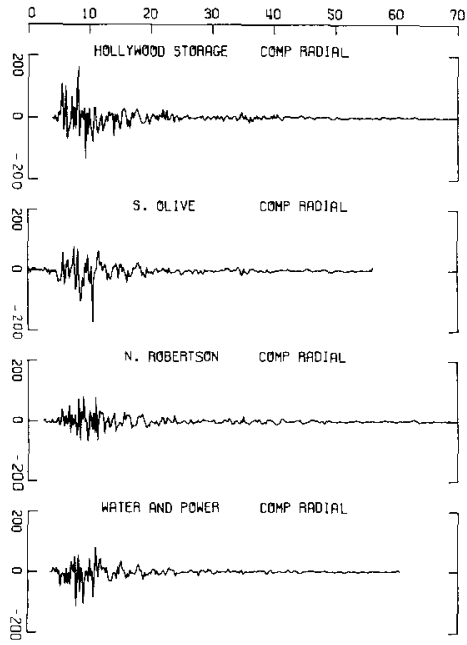

${ }_{\text {ACCELERATION IN CM/SECISEC. TIME IN SEC }}^{10}$ ?0
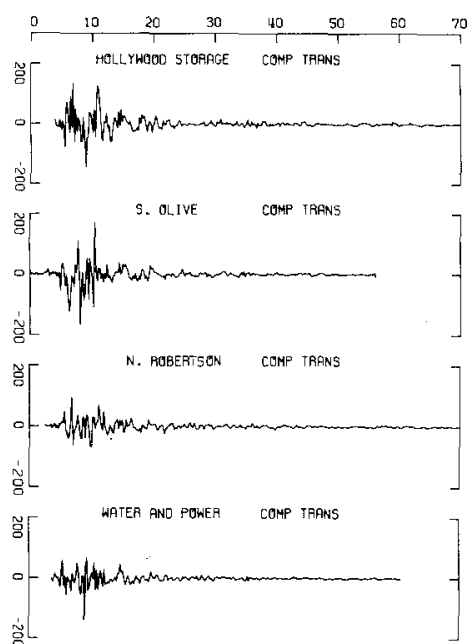

$\frac{1}{10}{ }_{\text {ACCELERATION IN CM/SEC/SEC, TIME IN SEC }}^{20}$ IO $^{30}$
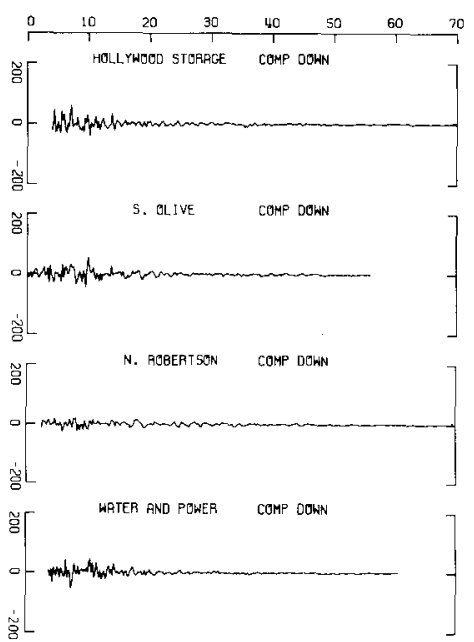

ACCELERATION IN CM/SEC/SEC, TIME IN SEC $\frac{10}{20}$ \%
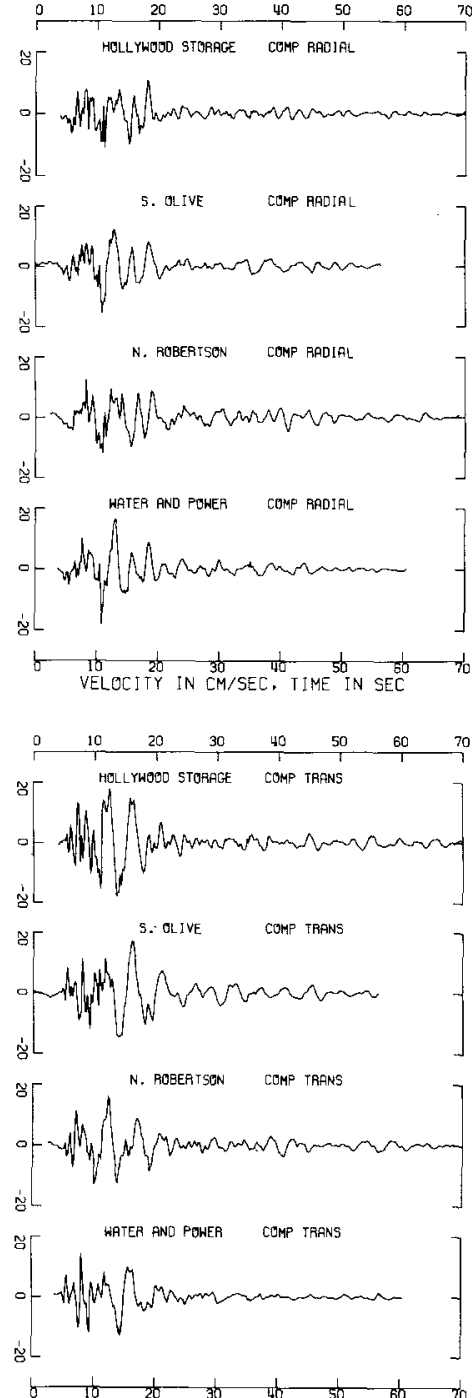

V. $\frac{10}{\text { VELOCITY IN CM/SEC. TIME IN SEC }}$ को
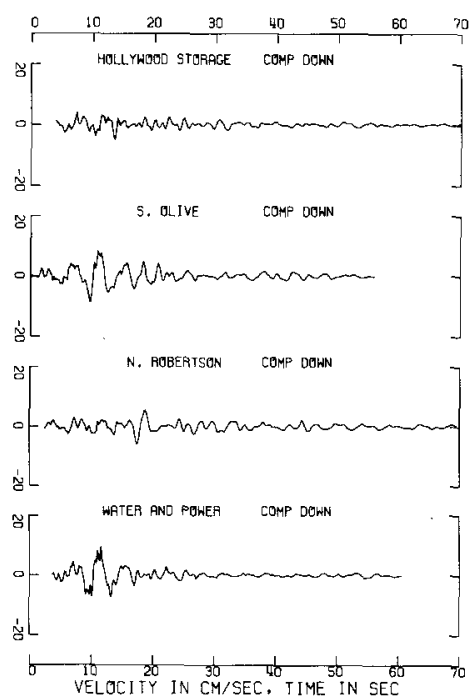
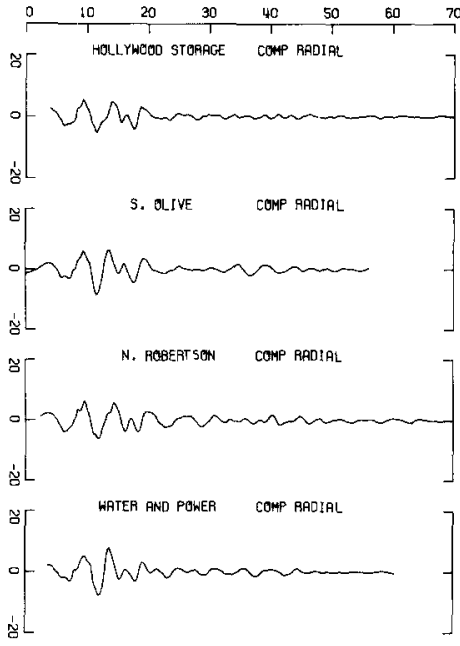

$\frac{10}{10} \frac{10}{20}$ DISPLACEMENT IN CM, TIME IN SEC.
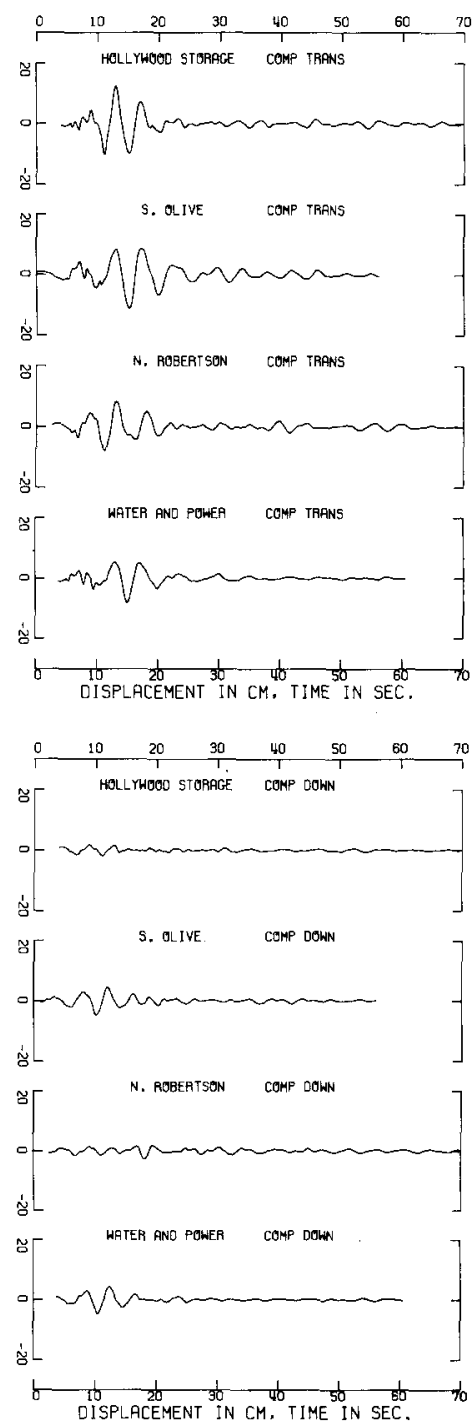

Fig, 10. Ground accelerations, velocities, and displacements recorded at the four stations in the Los Angeles and Hollywood area during the San Fernando, California, earthquake of 1971. 
Hollywood Storage suggests a possibility that the data processing errors may have also contributed to the overall amplitude variations seen in Figure 8. It has been recently pointed out by Trifunac and Lee (1974) and Hanks (1974) that the processing errors in computed displacements could be as large as $1 \mathrm{~cm}$ for periods of about $5 \mathrm{sec}$. The displacements in Figure 8 are about $1 \mathrm{~cm}$ and smaller. Thus, it may be possible that the recorded motions are actually quite coherent over distances close to $10 \mathrm{~km}$ and that most of the differences in Figure 8 arise from processing errors.

Figure 9 shows tha radial, transverse, and vertical ground motions during the Lytle Creek, 1970, California earthquake. The magnitude of this earthquake was only 5.4 and the moment an order of magnitude smaller than that of the San Fernando earthquake of 1971 (Table 2). Consequently, the computed ground velocity and displacements may be affected by the digitization noise so that no coherent signals are visually identifiable. Furthermore, the short length of the accelerograms (three of them shorter than $12 \mathrm{sec}$ ) seriously amplified the end effects of the digital filtering process (Hanks, 1974) and the resulting trace distortions are quite obvious for several curves in Figure 9.

The San Fernando, 1971, motions are shown in Figure 10. For this earthquake recorded amplitudes were well above the noise level, and the curves presented in this figure should be accurate representations of real ground motion (Trifunac and Lee, 1974; Hanks, 1974). The radial components of ground motion measured at the various sites as well as the transverse components show a high degree of similarity even when higherfrequency waves in velocity and displacement curves are compared. Also, there is little relative amplitude change when various stations are compared. The only significant difference that can be found for vertical components is that the pulse occurring at about $10 \mathrm{sec}$ on S. Olive and Water and Power records is absent at the N. Robertson and Hollywood Storage stations. Relative to the above discussion of the Borrego Mountain Earthquake data (Figure 8), the San Fernando motions (Figure 10) suggest a high degree of coherence for long-period waves, with essentially the same wave form propagating unchanged over this particular $10-\mathrm{km}$ stretch of the Los Angeles basin. Since there is little reason to assume that the region of coherence of long-period waves is dependent on the wave amplitude, this result suggests that the differences found for the Borrego Mountain earthquake data (Figure 8) are probably caused by digitization noise. According to the interpretation of Hanks (1974), the long-period large amplitudes occurring during the first $30 \mathrm{sec}$ of relative time in Figure 10 are the surface Love (transverse component) and Rayleigh (radial component) waves.

To study the frequency content of these ground motions, the accelerograms in Figures 8,9 , and 10 were analyzed. The Fourier amplitude spectra are shown in Figures 11A, B, C through 13A, B, C. Figure 11A shows the spectra of radial acceleration data obtained during the Borrego Mountain earthquake at the Hollywood Storage (HOLS), S. Olive (SOLV), N. Robertson (NROB), and Water and Power (WOPO) sites. The Fourier amplitudes clearly indicate almost identical spectra at HOLS and NROB from 0 to about $1.2 \mathrm{~Hz}$ and for SOLV and WOPO up to about $1.5 \mathrm{~Hz}$, in agreement with the time functions in Figure 8. Figure 11B shows good agreement between HOLS, SOLV, and WOPO up to about $1 \mathrm{~Hz}$, while Figure $11 \mathrm{C}$ shows nearly identical spectra even up to about $3 \mathrm{~Hz}$. The common feature of all spectra for the Borrego Mountain earthquake is that the spectral amplitudes display a rapid, exponential type decrease toward the highfrequency end. This can be interpreted to result from the fact that this earthquake occurred over $200 \mathrm{~km}$ away, a distance over which the high-frequency waves would be expected to diminish in amplitude proportional to $\exp (-\omega \Delta / 2 Q \beta)$, where $\omega$ is the circular frequency, $\Delta$ is the epicentral distance, $Q$ is the material constant, and $\beta$ is the wave velocity. In computing the spectra in Figures 11A, B, C through 13A, B, C, the 

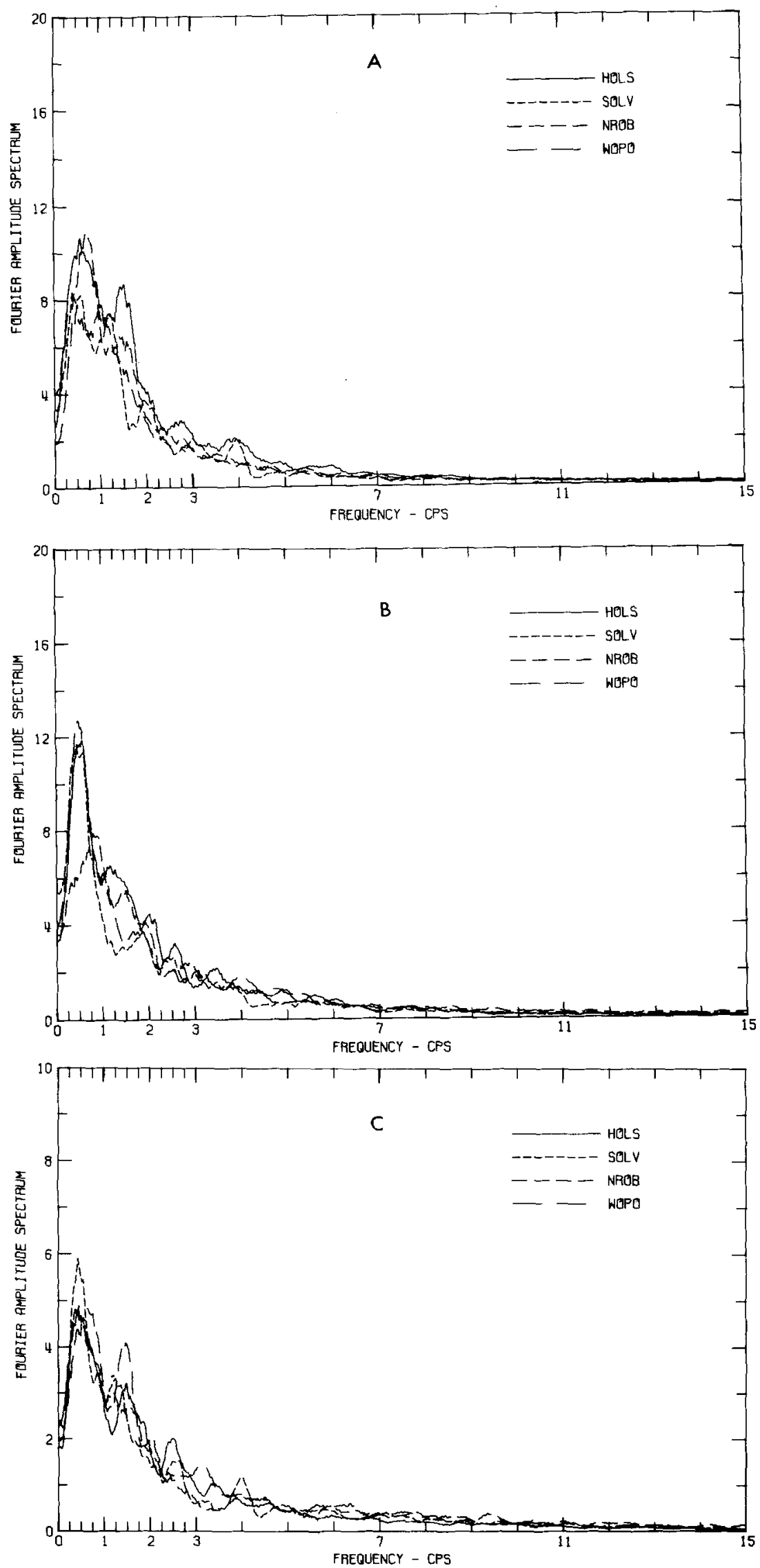

FIG. 11. Smoothed Fourier amplitude spectra-Borrego Mountain Earthquake. (A) radial comp. (B) trans. comp., (C) down comp. 

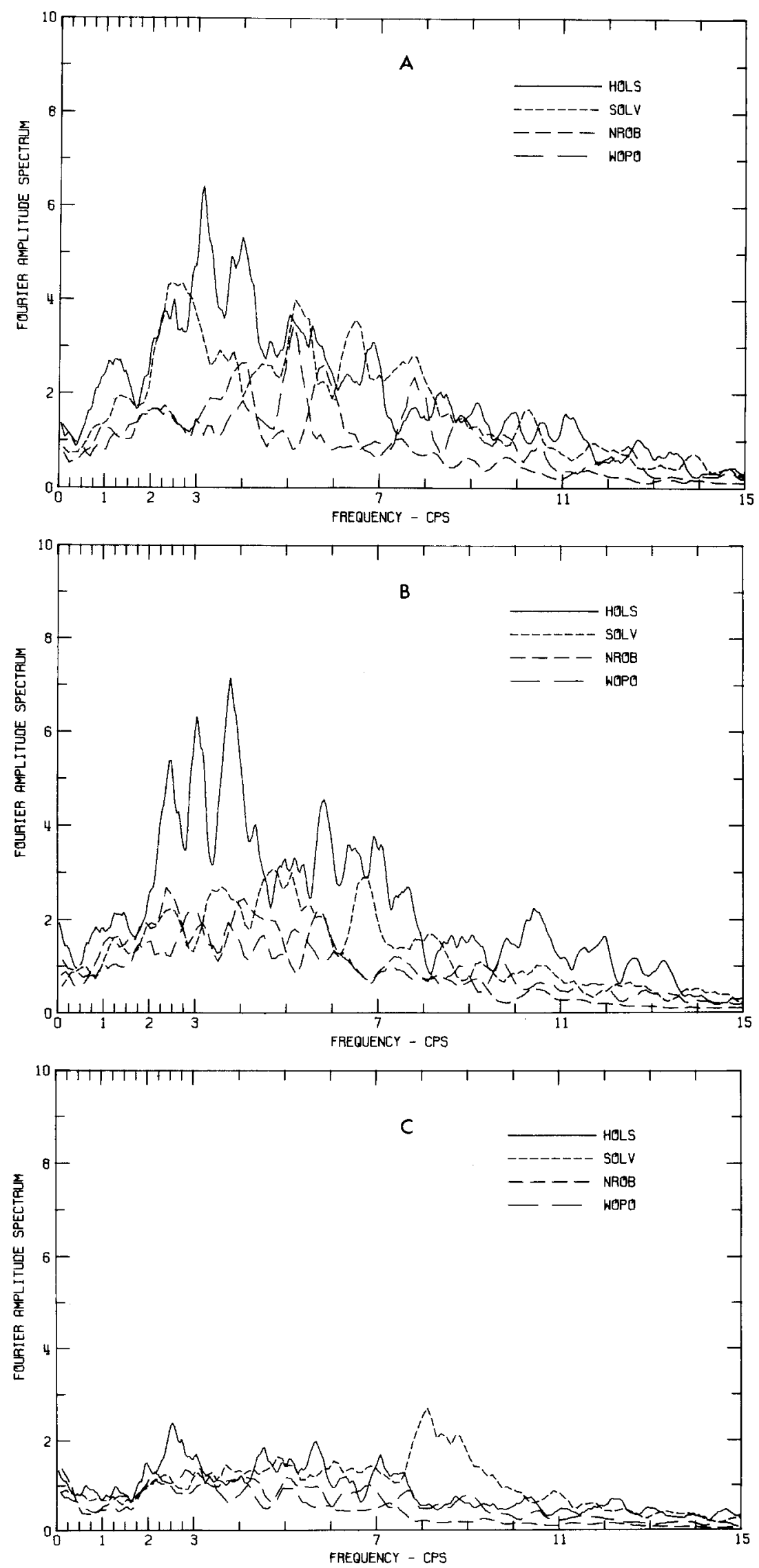

Fig. 12. Smoothed Fourier amplitude spectra-Lytle Creek Earthquake. (A) radial comp., (B) trans. comp., (C) down comp. 

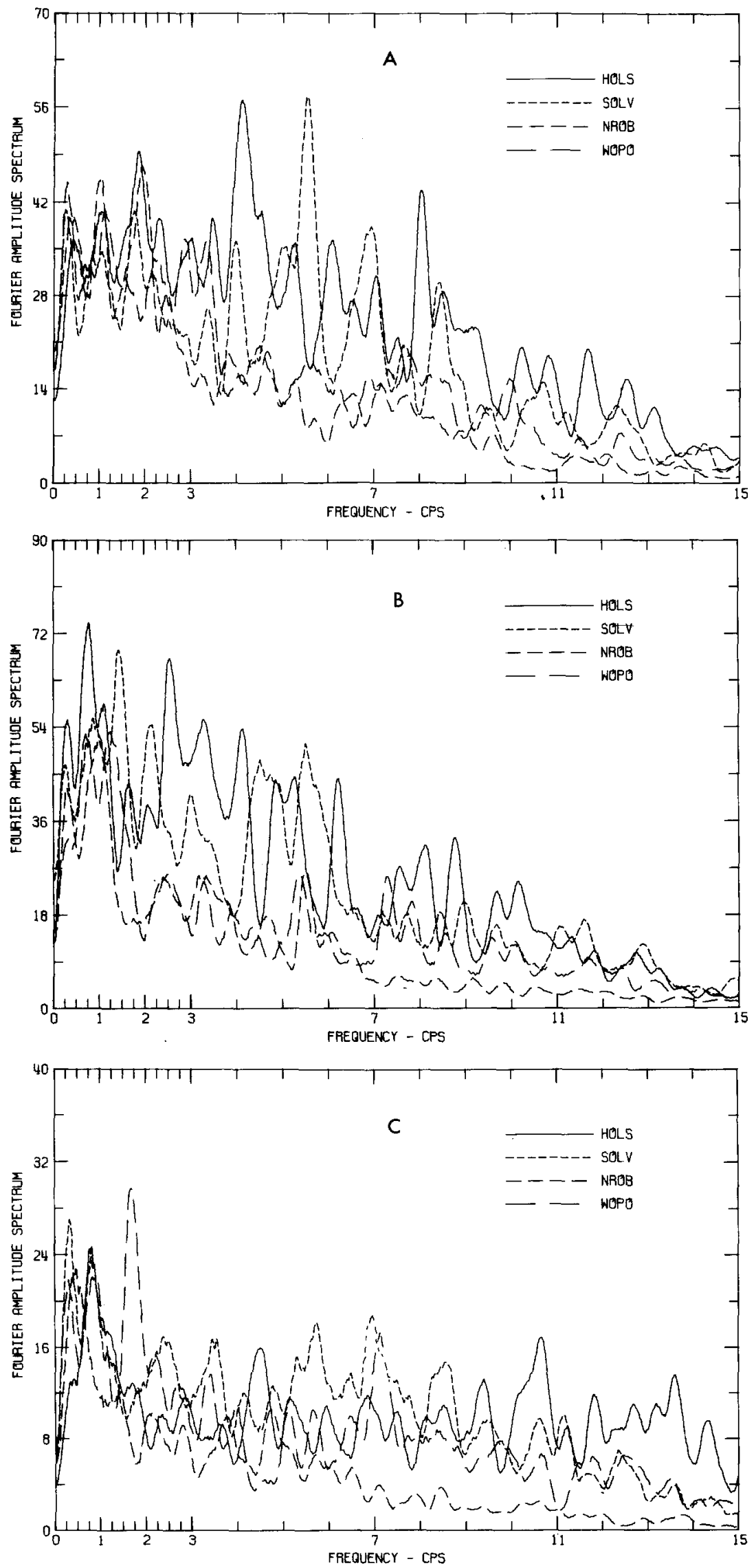

FIG. 13. Smoothed Fourier amplitude spectra-San Fernando Earthquake. (A) radial comp., (B) trans comp., (C) down comp. 
complete available record was transformed rather than the significant wave forms alone. In doing so we assume that the contributions of the low-amplitude motions (for example from 0 to about $20 \mathrm{sec}$ in Figure 8) preceding the strong surface-wave pulses are small.

Fourier spectra of the Lytle Creek earthquake accelerograms (Figures 12A, B, C) show that for several stations low-frequency spectral trends are quite similar up to about $2 \mathrm{~Hz}$. This earthquake occurred much closer than the Borrego Mountain shock and thus registered relatively larger amplitude high-frequency waves at all four stations (HOLS, SOLV, NROB, and WOPO). Since the Lytle Creek shock was characterized by a smaller source dimension and a moment about eight times smaller than that of the Borrego Mountain earthquake (Table 2), low-frequency spectral amplitudes at HOLS, SOLV, NROB, and WOPO should be an order of magnitude smaller than those for the Borrego Mountain shock. Analysis of amplitudes in Figures 11 A, B, C and 12A, B, C approximately agrees with this inference.

Figure 13A, B, C shows the Fourier amplitude spectra of the San Fernando accelerograms. The spectra of radial components at HOLS and NROB agree up to about $2 \mathrm{~Hz}$, while the spectra at all four stations agree well to about $1.2 \mathrm{~Hz}$. The spectra of transverse and vertical components agree only approximately between 0 and about $1 \mathrm{~Hz}$. In contrast to the Fourier amplitudes of the accelerograms for the Borrego Mountain earthquake, the data in Figure $13 \mathrm{~A}, \mathrm{~B}, \mathrm{C}$ show the significant contributions from the high-frequency waves. Again, this can be explained in good part by the relative proximity of the source of the earthquake energy release (Table 1).

\section{Strong-Motion Amplitudes And the Source Mechanism}

In the foregoing analysis of spectral amplitudes and time functions of ground motion, we indicated that the overall spectral trends appear to be determined by the parameters of the source mechanism and the source-to-station distance. We also argued that the local site conditions can affect the fine details of the frequency behavior of spectra but do not seem to change appreciably the overall spectral trends. This interpretation is in good agreement with our previous interpretation of similar data-sets recorded in Imperial Valley, California (Udwadia and Trifunac, 1973) and with the theoretical predictions of the spectral amplitudes based on simple representations of an earthquake source (Trifunac, 1973b). We now show that the data studied in this paper approximately follow these trends as well.

According to the dislocation theory (Brune, 1970), the peak ground accelerations should be mainly influenced by the stress drop of an earthquake (Trifunac, 1973b). According to that theory, for a station at a distance $R$ from the source, the peak acceleration will be given by the proportionality

$$
a_{\text {peak }} \propto \sigma \exp (-\omega R / 2 Q \beta)
$$

where $\sigma$ is the stress drop, $Q$ is the wave attentuation constant (about 200), and $\beta$ is the shear-wave velocity (about $3.5 \mathrm{~km} / \mathrm{sec}$ ). By using (1) it is possible to find the ratios of the recorded peak accelerations for two different earthquakes and compare this result with observations. This ratio is

$$
a_{1} / a_{2} \propto \sigma_{1} / \sigma_{2} \exp \left[-\omega\left(R_{1}-R_{2}\right) / 2 Q \beta\right] .
$$

To compare the peak accelerations at the four stations in the Los Angeles area (HOLS, SOLV, NROB, WOPO) for the recordings during the Lytle Creek and San Fernando earthquakes, we take: $\sigma_{1} \approx 50$ bars, $R_{1} \approx 40 \mathrm{~km}$, and $Q \approx 200$ for the San Fernando earthquake and $\sigma_{2} \approx 7$ bars, $R_{2} \approx 75 \mathrm{~km}$, and $Q \approx 200$ for the Lytle Creek earthquake. For a frequency of $5 \mathrm{~Hz}$, equation (2) gives $a_{1} / a_{2} \approx 15$, and for the frequency of $10 \mathrm{~Hz}$ 
it gives $a_{1} / a_{2} \approx 30$. Acceleration peaks for the San Fernando earthquake at the above four stations are of the order of $0.2 \mathrm{~g}$ (Figure 10) and about $0.01 \mathrm{~g}$ for the Lytle Creek earthquake (Figure 9), so that the observed ratio is about 20 , in good agreement with the estimated ratio using equation (2). It must be realized, of course, that this example is given only to illustrate the above statements on the dependence of the peak acceleration on the stress drop. Equation (1) is based on several crude assumptions (Trifunac, 1973b); it neglects many other important parameters and thus cannot be directly used for prediction of peak accelerations. We do not attempt to perform similar comparisons for the Borrego Mountain earthquake data, since the accelerograms for this earthquake consist essentially of surface waves only and for these waves simple theories (Trifunac, 1973b) on which equation (1) is based do not apply.

At the other end of the spectrum for frequencies tending to zero, the spectral amplitudes should be proportional to the seismic moment. Since the surface-wave contributions represent the significant fractions of low-frequency ground motions at the distances in question (Table 1), we can expect that the peak displacement amplitudes, $d_{\max }$, multiplied

TABLE 4

Proportionality Constants from Three Earthquakes for Approximate Scaling of THE STRONG-Motion Data

\begin{tabular}{|c|c|c|c|c|}
\hline Earthquake & $\begin{array}{c}\bar{R}^{*} \\
\text { Average Distance } \\
\text { to HOLS, SOLV } \\
\text { NROB, and WOPO } \\
(\mathrm{km})\end{array}$ & $\begin{array}{c}M_{0} \\
\text { Seismic } \\
\text { Moment, } \\
\times 10^{24} \\
(\text { dyne-cm) }\end{array}$ & $\begin{array}{c}d_{\max }{ }^{\dagger} \\
\text { Peak } \\
\text { Displicement } \\
(\mathrm{cm})\end{array}$ & $\frac{d_{\max } \sqrt{R}}{d_{\max }^{\circ} \sqrt{R^{\circ}}}$ \\
\hline Lytle Creek & $\bar{R}^{\circ} \approx 75$ & 1 & $d_{\max }^{\circ} \approx 0.1$ & 1 \\
\hline Borrego Mountain & $\sim 225$ & $36-100$ & $\sim 1.5$ & 26 \\
\hline San Fernando & $\sim 40$ & $47-130$ & $\sim 10$ & 74 \\
\hline
\end{tabular}

*Approximate average distance from the epicenter to HOLS, SOLV, NROB, and WOPO.

†See Figures 8, 9, and 10.

by the square root of the distance, $R$, should be proportional to the seismic moment $M_{o}$, that is

$$
M_{o} \propto d_{\max } \sqrt{ } R .
$$

This quantity is calculated in Table 4 and normalized with respect to $\bar{R}_{0} \approx 75 \mathrm{~km}$ and $d_{\max }^{\circ} \approx 0.1 \mathrm{~cm}$ for the Lytle Creek earthquake. It may be seen from the last column in Table 4 that these dimensionless ratios are indeed proportional to the seismic moment $M_{0}$.

The above approximate analysis points out again that the overall spectral trends are scaled to an appreciable extent by the parameters characterizing the earthquake source mechanism (Trifunac, 1973b). To describe the source mechanism completely it is, of course, necessary to determine many pertinent parameters and to describe the source geometry accurately. In this approximate analysis we restrict our attention to the simplest description of an earthquake source that depends on two parameters only, the seismic moment $M_{o}$ and the stress drop $\sigma$. Further refinement which would, for example, involve description of the fault plane and the velocity of dislocation growth would enable one to model the peaks and troughs in the low-frequency end of the observed spectra, but would require a more detailed analysis, which is beyond the scope of this paper. 


\section{CONCLUSIONS}

1. No identifiable site periodicities independent of the direction from which seismic waves arrive could be found for the strong-motion accelerograph sites studied in this paper. Spectral amplitudes are strongly dependent on the source mechanism and the effects of the transmission path and not the local site conditions only.

2. Radial, transverse, and vertical motions at several stations in the central Los Angeles area recorded during the same earthquake are coherent in the frequency band from 0 to about $1 \mathrm{~Hz}$ over distances up to about $10 \mathrm{~km}$. For stations less than several kilometers away coherent motions can include frequencies as high as $3 \mathrm{~Hz}$. With the present methods of accelerogram processing (Trifunac and Lee, 1973) to study coherence of ground motion, displacement amplitudes have to exceed about $1 \mathrm{~cm}$ to be above the digitization noise.

3. At distances larger than several source dimensions, surface waves may play an important role is shaping the character of strong ground motion. For the Borrego Mountain and the San Fernando earthquakes the records studied indicate that surface waves represented by far the most important contribution to the motions observed in the Los Angeles and Hollywood areas. Although the same was probably true for the Lytle Creek earthquake, the small displacement amplitudes buried under the processing noise did not permit positive identification.

4. Approximate analysis of gross spectral features shows that the long-period ground displacements can be approximately scaled by the seismic moment, while the highfrequency amplitudes of ground acceleration can be scaled approximately by the stress drop. This observation is in agreement with the predicted spectral trends based on the simple earthquake dislocation theory (Trifunac, 1973b).

5. The lack of repeated spectral peaks that might be associated with local soil conditions at the six stations studied in this paper suggests that the seismic regionalization methods based on the simple one-dimensional amplification characteristics of local soil conditions probably do not represent a meaningful approach to this important problem for the Los Angeles area.

\section{ACKNOWLEDGMENTS}

We thank A. G. Brady, T. C. Hanks, D. E. Hudson, and J. E. Luco for critical reading of the manuscript and for many valuable suggestions. This research was supported by grants from the National Science Foundation and by the Earthquake Research Affiliates Program at the California Institute of Technology.

\section{REFERENCES}

Abubakar, I. (1962). Reflection and refraction of plane $S H$ waves at irregular interfaces, I, II, Phys. Earth 10, 1-14 and 15-20.

Aki, K. (1957). Space and time spectra of stationary stochastic waves, with special reference to microtremors, Bull. Earthquake Res. Inst., Tokyo Univ. 35, 415-456.

Aki, K. (1968). Seismic displacements near a fault, J. Geophys. Res. 72, 1217-1231.

Aki, K. and K. Larner (1970). Surface motion of a layered medium having an irregular interface due to incident plane $S H$ waves, Geophys. Res. 75, 933-954.

Alaska Earthquake (1964). The Prince William Sound, Alaska, earthquake of 1964 and aftershocks, U.S. Department of Commerce, Environmental Science Services Administration, Washington, D.C.

Boore, D. M. (1972). A note on the effect of simple topography on seismic SH waves, Bull. Seism. Soc. Am. 62, 275-284.

Brune, J. N. (1970). Tectonic stress and the spectra of seismic shear waves from earthquakes, J. Geophys. Res. 75, 4997-5009. 
Byerly, P. (1947). The periods of local earthquake waves in central California, Bull. Seism. Soc. Am. 37, 291-297.

Duke, C. M. (1958). Bibliography of effects of soil conditions on earthquake damage, Earthquake Engineering Research Institute, San Francisco.

Gupta, R. N. (1966). Reflection of plane elastic waves from transition layers with arbitrary variation of velocity and density, Bull. Seism. Soc. Am. 56, 633-642.

Gutenberg, B. (1957). Effects of ground on earthquake motion, Bull. Seism. Soc. Am. 47, 221-250.

Hanks, T. C. and M. Wyss (1972). The use of body-wave spectra in determination of seismic source parameters, Bull. Seism. Soc. Am. 62, 561-590.

Hanks, T. C. (1975). Strong ground motion following the San Fernando, California, earthquake. 1. Ground displacements (in press).

Haskell, N. A. (1962). Crustal reflection of plane $P$ and $S V$ waves, J. Geophys. Res. 67, 4751-4767.

Haskell, N. A. (1969). Elastic displacements in the near-field of a propagating fault, Bull. Seism. Soc. Am. 59, 865-908.

Herrera, I. and E. Rosenblueth (1965). Response spectra in stratified soil, Proc. World Conf. Earthquake Eng. 3rd, 1, 44-60.

Hudson, D. E., A. G. Brady, and M. D. Trifunac (1969). Strong-motion earthquake accelerograms, digitized and plotted data, Vol. I, Part A, Earthquake Eng. Res. Lab., EERL 69-20, Calif. Inst. of Tech., Pasadena.

Hudson, D. E., A. G. Brady, M. D. Trifunac, and A. Vijayaraghavan (1971). Strong-motion earthquake accelerograms, corrected accelerograms and integrated velocity and displacement curves, Vol. $I I$, Part A, Earthquake Eng. Res. Lab., EERL 71-51, Calif. Inst. of Tech. Pasadena.

Hudson, D. E. (1972). Local distribution of strong earthquake ground motion, Bull. Seism. Soc. Am. 62, 1765-1786.

Hudson, D. E., M. D. Trifunac, and A. G. Brady (1972a). Strong-motion earthquake accelerograms, response spectra, Vol. III, Part A, Earthquake Eng. Res. Lab., EERL 72-80, Calif. Inst. of Tech. Pasadena.

Hudson, D. E., M. D. Trifunac, F. E. Udwadia, A. Vijayaraghavan, and A. G. Brady (1972b). Strongmotion earthquake accelerograms, Fourier spectra, Vol. IV, Part A, Earthquake Eng. Res. Lab., EERL 72-100, Calif. Inst. of Tech., Pasadena.

Hudson, J. A. (1962). The total internal reflection of $S H$ waves, Geophys. J. 6, 509-531.

Idriss, I. M. and H. B. Seed (1967). Response of horizontal soil layers during earthquakes, Soil Mechanics and Bituminous Materials Research Laboratory, Univ. of California, Berkeley.

Jennings, P. C. (Editor) (1971). San Fernando earthquake of February 9, 1971, Earthquake Eng. Res. $L a b .$, EERL 71-02, Calif. Inst. of Tech., Pasadena.

Kanai, K. (1957). The requisite conditions for predominant vibration of ground, Bull. Earthquake Res. Inst., Tokyo Univ. 35, 457.

Kanai, K., T. Tanaka, and T. Suzuki (1953). Relation between the earthquake damage and the nature of the ground, Bull. Earthquake Res. Inst., Tokyo Univ. 31, 57-62.

Kanai, K. and T. Tanaka (1961). On microtremors, VIII, Bull. Earthquake Res. Inst., Tokyo Univ. 39, $97-115$.

Lee, K. L. and E. J. Monge (1966). Effect of soil conditions on damage in the Peru earthquake of October 17, 1966, Univ. of California, Los Angeles.

Richter, C. F. (1958). Elementary Seismology, Freeman and Co., San Francisco.

Sakurai, A. and T. Takahashi (1971). Amplification of earthquake ground motion in surface ground layers deriving from the observations of the Matsushiro earthquakes, Trans. Jap. Soc. Civil Eng. 3, Part 1,10-11.

Sato, R. (1963). Diffraction of $S H$ waves at an obtuse angled corner, J. Phys. Earth 11, 1-17.

Schnabel, P., H. H. Seed, and J. Lysmer (1972). Modification of seismograph records for effects of local soil conditions, Bull. Seism. Soc. Am. 62, 1649-1664.

Smith, M. B. (1964). Map showing distribution and configuration of basement rocks in California, Oil and Gas Investigations, Map OM-215, U.S. Geological Survey, Washington, D.C.

Sozen, M. A., P. C. Jennings, R. B. Matthiesen, G. W. Housner, and N. M. Newmark (1968). Engineering report on the Caracas earthquake of 29 July 1967, National Academy of Sciences, Washington, D.C.

Suzuki, T. (1932). On the angle of incidence of the initial motion observed at Hôngo and Mitaka Bull. Earthquake Res. Inst., Tokyo Univ. 10, 517-530.

Trifunac, M. D. (1971a). Surface motion of a semi-cylindrical alluvial valley for incident plane $S H$ waves, Bull. Seism. Soc. Am. 61, 1739-1753.

Trifunac, M. D. (1971b). Response envelope spectrum and interpretation of strong earthquake ground motion, Bull. Seism. Soc. Am. 61, 343-356. 
Trifunac, M. D. (1972a). Stress estimates for San Fernando, California, earthquake of February 91971 : Main event and thirteen aftershocks, Bull. Seism. Soc. Am. 62, 721-750.

Trifunac, M. D. (1972b). Tectonic stress and source mechanism of the Imperial Valley, California, earthquake of 1940, Bull. Seism. Soc. Am. 62, 1283-1302.

Trifunac, M. D. (1973a). A note on scattering of plane $S H$ waves by a semi-cylindrical canyon, Intern. J. Earthquake Eng. and Struct. Dyn. 1, 267-281.

Trifunac, M. D. (1973b). Analysis of strong earthquake ground motion for prediction of response spectra, Intern. J. Earthquake Eng. and Struct. Dyn. 2, 59-69.

Trifunac, M. D. and V. W. Lee (1973). Routine computer processing of strong-motion accelerograms, Earthquake Eng. Res. Lab., EERL 73-03, Calif. Inst. of Tech., Pasadena.

Trifunac, M. D. (1974). A three-dimensional dislocation model for the San Fernando, California, earthquake of February 9, 1971, Bull. Seism. Soc. Am. 64, 149-172.

Trifunac, M. D. and V. W. Lee (1974). A note on the accuracy of computed ground displacements from strong motion accelerograms, Bull. Seism. Soc. Am. 64, 1209-1220.

Tsai, N. C. (1969). Influence of local geology on earthquake ground motion, Ph.D. Thesis, Calif. Inst. of Tech., Pasadena.

Udwadia, F. E. (1972). Investigation of earthquake and microtremor ground motions, Earthquake Eng. Res. Lab., EERL 72-02, Calif. Inst. of Tech., Pasadena.

Udwadia, F. E. and M. D. Trifunac (1973), Comparison of earthquake and microtremor ground motions in El Centro, California, Bull. Seism. Soc. Am. 63, 1227-1253.

Waseda University Publication (1966). Special issue on Niigata earthquake, Bull. Seism. Eng. Res. Lab. 34.

Wiggins, J. H. (1964). Effect of site conditions on earthquake intensity, J. Struct. Div., Am. Soc. Civil Engrs. 90, 279-314.

Wyss, M. and T. C. Hanks (1972). The source parameters of the San Fernando earthquake (February 9, 1971) inferred from teleseismic body waves, Bull. Seism. Soc. Am. 62, 591-602.

EARTHQUAKe EngineERING Research Laboratory

California INSTITUte of Technology

Pasadena, California 91109.

Manuscript received January 31, 1974. 